\title{
Sancho Iv, María de Molina y la promoción de la Orden de Predicadores: modelo de realeza y cultura política*
}

Sancho IV, María de Molina and the promotion of the Order
of Preachers: royal model and political culture

María del Mar GRAÑA CID

Departamento de Sagrada Escritura e Historia de la Iglesia

Universidad Pontificia Comillas (Madrid)

https://orcid.org/0000-0001-6706-2298

mar.grana@comillas.es

\begin{abstract}
The analysis of the link between Sancho IV and María de Molina with the Mendicant Orders shows their preference for the Order of Preachers. This article analyzes that relationship from the point of view of the promotion of convents and monasteries, trying to reveal the keys to the royal model and the political culture promoted by both monarchs. Their relationships with Dominican establishments are analyzed separately because both of them took similar forms and shared objectives, but also showed notable differences. Another characteristic aspect was the development of a courtly culture in a Dominican key.
\end{abstract}

Keywords: Sancho IV; María de Molina; Order of Preachers; royal model; political culture; queenship; convents.
Resumen: El análisis del vínculo entre Sancho Iv y María de Molina con las órdenes mendicantes muestra su preferencia por la Orden de Predicadores. Este trabajo analiza dicha relación desde el punto de vista de la promoción de conventos y monasterios intentando desvelar las claves del modelo de realeza y de la cultura política impulsados por ambos monarcas. Para ello, se analizan por separado sus relaciones con los establecimientos dominicos. Ambos compartieron formas y objetivos, pero también mostraron llamativas diferencias. Otro aspecto característico fue el desarrollo de una cultura cortesana en clave dominica.

Palabras clave: Sancho Iv; María de Molina; Orden de Predicadores; modelo de realeza; cultura política; reginalidad; conventos.

* Este trabajo es fruto del proyecto de investigación «Paisajes monásticos. Representaciones y virtualizaciones de las realidades espirituales y materiales medievales en el Mediterráneo occidental (siglos VI-XVI)», Ministerio de Ciencia, Innovación y Universidades (PGC2018-095350-B-100). 
Entre los aspectos característicos del reinado de Sancho IV destaca la querencia que tanto él como la reina María de Molina mostraron por las órdenes mendicantes, a las que favorecieron de diversas formas ${ }^{1}$. Siendo esto así, hay sin embargo indicios de peso para afirmar la mayor inclinación de la pareja por la Orden de Predicadores. Entre otras cuestiones, al hecho de que una primera valoración numérica de los documentos arroje un saldo favorable a la institución dominica cabría sumar que las únicas fundaciones realizadas por el rey y la reina fuesen de esta orden ${ }^{2}$. Ciertamente, se ha venido destacando la inclinación dominica del $\mathrm{rey}^{3}$, aunque sobre todo los cronistas han subrayado más la de la reina, considerada «única bienhechora»y «verdadera madre» ${ }^{4}$.

Interesa analizar en forma, fondo y causas esta inclinación preferente de la Corona castellano-leonesa en el tránsito del siglo XIII al XIV. A ello se consagran estas páginas. Entendemos además que es preciso estudiar las acciones de Sancho IV y las de María de Molina. La notable involucración de ambos en beneficio de la orden dominica ofrece fenomenologías coincidentes, pero también dispares. Llama la atención el contraste entre la intensa acción pública pro-dominica de don Sancho y el peso de lo franciscano en su vida personal, concretamente en sus disposiciones funerarias ${ }^{5}$. En cambio, si bien doña María desplegó una intensa actuación pro-mendicante que benefició a los distintos institutos englobados bajo esta denominación, mantuvo un vínculo estrecho con la Orden de Predicadores hasta el final de su vida y ofreció un acento devoto más marcado. Podría pensarse en un reparto complementario de esferas, pública el rey y personal y espiritual la reina, pero el asunto es más complejo.

1 Peter Linehan, La Iglesia española y el papado en el siglo XIII, Salamanca, 1975, p. 195ss; José Manuel NieTo Soria, Sancho IV de Castilla (1284-1295), Gijón, 2014, p. 195.

2 Las cifras de documentos editados son contundentes: el 87,3\% de los que Sancho IV dirigió a frailes y monjas mendicantes fueron para la Orden de Predicadores. Además, el rey fundó Santo Domingo de Benavente y proyectó otra fundación en Oviedo.

3 Juan López, Tercera parte de la bistoria general de Sancto Domingo y de su Orden de Predicadores, Valladolid, 1613, libro 1, p. 274; Mercedes GAIBROIS DE BALLESTEROS, Historia del reinado de Sancho IV de Castilla, 3 t., t. 1, Madrid, 2019, p. 48; Francisco García-SERrano, Preachers of the City. The Expansion of the Dominican Order in Castile (1217-1348), New Orleans, 1997, p. 72.

4 En Castilla. Hernando del CASTILlo, Segunda parte de la bistoria general de Sancto Domingo y de su Orden de Predicadores, Valladolid, 1592, p. 113.

5 Dispuso ser enterrado con el cordón franciscano y probablemente también con el hábito. Mercedes GaIBROIS, Historia... [ver n. 3], t. 2, p. 395. Salustiano Moreta VelaYos, Notas sobre el franciscanismo y el dominicanismo de Sancho IV y María de Molina, en VI Semana de Estudios Medievales, Logroño, 1996, pp. 179-181. 
Esta complejidad exige focalizar el análisis y por ello nos centraremos en un aspecto del vínculo con los dominicos, la promoción de conventos y monasterios. Buscamos valorar las formas de implicación de los reyes y los fines que perseguían, en sus similitudes y diferencias, e intentar explicar desde esta perspectiva conventual las razones de su inclinación preferente por la orden. Estos objetivos se inscriben en un marco de indagación más amplio. Entre las diversas implicaciones de la fundación o mejora de los establecimientos religiosos están las que tienen que ver con el poder y la política, desde los simbolismos representativos a la praxis ejecutiva y relacional. El hecho de que tanto el rey como la reina se involucrasen ofrece un valioso telón de reflexión sobre las formas de incidencia de los agentes regios en el modelo político. En el caso de estos monarcas resulta muy pertinente dado el elevado protagonismo alcanzado por la reina, tal como viene subrayando la investigación reciente en torno al «molinismo» ${ }^{6}$, y su peso esencial en la historia del mecenazgo y patronazgo femeninos en la península ${ }^{7}$. Por ello, perseguimos valorar los modelos de realeza y de cultura política que se plasmaron en la promoción conventual o que esta contribuyó a construir, y trazar conexiones comparativas con los reinados anteriores y posteriores a fin de caracterizar elementos de continuidad, novedades y posibles rupturas.

Con estas páginas me sumo a la conmemoración de santo Domingo, pero también deseo rendirle un pequeño homenaje a María de Molina en el séptimo centenario de su muerte (1321).

\section{EL DOMINICANISMO DE SANCHO IV: LEGITIMIDAD Y SOBERANÍA}

Don Sancho se involucró en la promoción de la orden desde que era infante mostrando notorios intereses políticos. Algo asimismo perceptible en la interacción entre los miembros de la familia real en su impulso dominico.

6 Véanse sobre todo los trabajos de Fernando Gómez Redondo. Entre otros: Fernando GómEZ REDONDO, El molinismo: un sistema de pensamiento letrado (1284-1350), en Antonia MARTÍNEZ PÉREZ y Ana Luisa BAQUERO EsCUDERO (eds.), Estudios de literatura medieval. 25 años de la Asociación Hispánica de Literatura Medieval, Murcia, 2012, pp. 43-73, p. 68. Sin olvidar el trabajo clásico de Mercedes Gaibrois De Ballesteros, María de Molina. Tres veces reina, Madrid, 1967. Entre las aproximaciones recientes, María Antonia CARMONA RUIZ, María de Molina, Barcelona, 2005.

7 Patricia Rochwert-Zuili, El mecenazgo y patronazgo de María de Molina. Pruebas e indicios de unos recursos propagandísticos y dinásticos, en E-Spania (2016), p. 12. 


\section{I.1. Conventos dominicos y cuestión sucesoria}

Por lo que sabemos, don Sancho fue el primer infante fundador de un convento mendicante en Castilla-León. Su inicial promoción dominica adquiere un relieve peculiar en conexión con la sucesión al trono porque fue en 1276, tras proclamarse heredero sin respaldo formal ${ }^{8}$, cuando inició la fundación de un convento de frailes en su villa de Benavente. La acción fundadora, además de vincular su imagen pública al ejercicio del poder, articulaba distintas esferas políticas y construía una red de lealtades.

Es conocida la capacidad propagandística de las fundaciones. Prestigiaban a los fundadores religiosa y socialmente por ser una obra pía y mostrar la magnificencia asociada al poder. Conventos y monasterios constituían su manifestación perpetua, material y simbólica, con funciones de representación y memoria. El infante ganaba autoridad pública y asociaba estas implicaciones a su posición sucesoria al presentarse como hijo mayor y heredero de Alfonso X y lo hacía en el reino de León, donde precisamente se había destacado el rey Sabio en la promoción de conventos dominicos. La singularización de la figura regia que esto había procurado pudo ser aprovechada por don Sancho para enfatizar la conexión con su padre. La asociación entre legitimidad, filiación y conventos permitiría hablar de una estrategia de filiación conventual.

Además, el hecho de fundar manifestaba y fortalecía los lazos señoriales. El concejo de Benavente era incluido en este entramado de referencias porque don Sancho lo responsabilizaba de la materialización del proyecto evidenciando la fidelidad que se le debía9 ${ }^{9}$ Al seguir su orden de solicitar a las autoridades dominicas el envío de frailes fundadores, los miembros del concejo entendían que la fundación sería a gran servicio de Dios, salud de sus almas «e a provecho de nos e de nuestra villa e de nuestro pueblo». En marzo de 1277, el infante situaba bajo su protección al naciente convento. En 1279 ordenaba al concejo que seleccionase tasadores de acuerdo con los frailes para que la comunidad tuviese morada adecuada. En 1281 habría culminado la fundación ${ }^{10}$.

8 José Manuel NieTo Soria, Sancho IV ... [ver n. 1], p. 28.

9 José LEDo DEL POZO, Historia de la nobilísima villa de Benavente, Salamanca, 1970, p. 197. La cuestión de la fidelidad relacionada con la fundación conventual, en Juan LóPEZ, Tercera... [ver n. 3], libro 1, p. 318.

10 Manuel M $\mathrm{M}^{\mathrm{a}} \mathrm{DE}$ LOS HoYOs, Material inédito dominicano español. Registro documental, t. 2, Valladolid, 1962, p. 294; Francisco GARCÍA-SERrano, Preachers... [ver n. 3], p. 67; Raquel del Carmen FERNÁNDEZ RuIZ, Colección diplomática del monasterio de Santo Domingo de Benavente (1228-1390), 
Don Sancho no cedió terrenos o edificios, se limitó a poner en marcha el proceso. Ello no invalidaba el vínculo personal que reportaban la responsabilidad fundadora y la declaración de protección. Destaquemos la dimensión personalista en un marco carente de referencias dinásticas, lo cual singularizaba su figura y poder señorial. Asimismo, se presentaba como promotor de las villas, sus gobiernos y comunidades. Al facultar la interacción entre los frailes y el concejo, favorecía el funcionamiento y percepción social de la colectividad urbana, que habitualmente se asociaba a aquellos ${ }^{11}$.

La fundación de Benavente completaba el esquema organizativo de la provincia dominica de Hispania, que en el capítulo celebrado un año antes había creado la vicaría de León, coincidente con el reino leonés. Esta cercanía cronológica no parece casual. El nuevo convento ampliaba la implantación de la Orden de Predicadores en el área zamorana y contribuía a incrementar su importancia; además, surgía en relación con Santo Domingo de Zamora, residencia conventual del vicario, fray Munio de Zamora. A ambos dirigió su solicitud de frailes fundadores el concejo de Benavente ${ }^{12}$. Sabemos que fray Munio llegó a situarse al servicio de don Sancho ${ }^{13}$, pero no si fue en este momento. En todo caso, el infante daba los pasos necesarios para forjar una incipiente red clientelar con los establecimientos zamoranos en su calidad de protector y promotor.

Si estas acciones contribuían a construir la figura política del infante, el hecho de que la fundación benaventana se desarrollase en interacción con sus padres aporta otras claves. También en 1276, Alfonso X otorgaba un importante privilegio eximiendo a los dominicos del portazgo por libros, paños, pergaminos, viandas y otras cosas para su consumo ${ }^{14}$, y la reina Violante impulsaba la

Benavente, 2000, núms. 6, 8 y 9, pp. 45-48; Manuel GonZÁLEZ JimÉnEZ, Sancho IV, infante, en Historia, Instituciones, Documentos, 28 (2001), núms. 13 y 35.

11 En este caso, el obispo involucró al colectivo vecinal permitiendo a los frailes recibir su caridad libremente Raquel del Carmen FERNÁNDEZ RUIZ, Colección... [ver n. 10], núm. 7, p. 46.

12 Juan López, Tercera... [ver n. 3], libro 1, pp. 318-319; Manuel Mª DE LOS Hoyos, Material inédito... [ver n. 10], t. 1, Madrid, 1961, p. 38.

13 Santiago Domínguez SÁNCHEZ, El convento dominico de San Pablo de Palencia (1220-1600). Breve reseña bistórica y colección diplomática, t. 1, Salamanca, 2017, núm. 22, pp. 97-98. Sobre el vínculo de servicio de los frailes con la Corona: Guillermo NIEva OCAMPO, Los dominicos en Castilla. La génesis de una corporación privilegiada en la Baja Edad Media, en Guillermo NIEVA OCAMPO et al. (eds.), Servir a Dios y servir al rey: el mundo de los privilegiados en el ámbito bispánico (siglos XIII-XVIII), Salta, 2011, pp. 13-47.

14 Santiago Domínguez SÁNCHEZ, La colección de pergaminos de San Pablo de Valladolid (1276-1605): un vademécum para la diplomática procesal pontificia, León, 2020, núm. 3, p. 56. 
fundación de San Pablo de Valladolid como señora de la ciudad ${ }^{15}$. En 1277, don Sancho tomaba dos establecimientos dominicos bajo su protección: Benavente y Caleruega. El rey, previendo no poder acabar el que denominaba «monasterio real» ${ }^{16}$, había pedido a su hijo que se obligase a terminar la edificación del segundo cuando él muriese. Don Sancho se comprometió a ello y puso al monasterio bajo su protección; en 1279 confirmaba un privilegio del rey tras ser reconocido heredero en $1278^{17}$. Benavente muestra esta misma sintonía en la promoción conventual: a comienzos de los 70, Alfonso X tomó bajo su protección a las clarisas y quizá doña Violante impulsase a los franciscanos ${ }^{18}$. La opción dominica del infante completaba la presencia mendicante en la villa y lo identificaba con los reyes.

La Orden de Predicadores estaba vinculada a la Corona y a Castilla desde que Fernando III se proclamase su protector en todo el reino (1222), pero fue Alfonso X quien expresamente le otorgó una función dinástica e identificativa. En los documentos fundacionales de Santo Domingo de Caleruega había subrayado la obligación de las monjas de rezar por la familia real y la dinastía y recordaba que el fundador de la orden, el ya canonizado Domingo de Guzmán, era natural de Castilla ${ }^{19}$. La identificación entre la dinastía y el reino castellano se fortalecía a través del vínculo dominico, así como la propia identidad de ambos.

Fundar un convento dominico activaba potentes mecanismos simbólicos de identificación con el orden dinástico y, por tanto, de legitimidad. Fernando III y Alfonso X habían promovido la implantación y sobre todo el segundo la creación de conventos, de modo que la acción de don Sancho dibujaba líneas de continuidad con su padre. Tampoco parece casual la sintonización entre el ejercicio del poder señorial, la autoridad concejil y los dominicos, como si la acción fundadora conciliase estas tres dimensiones y plasmase la política mendicante desarrollada por el rey Sabio en el realengo. Aunque, ciertamente, el particularismo local y

15 Además, concedía que los frailes pudiesen comprar heredamientos o recibirlos de otros. Santiago DomíngueZ SÁNCHEZ, La colección de pergaminos de San Pablo de Valladolid... [ver n. 14], núms. 1 y 2, pp. 55-56.

16 Hernando del Castillo, Primera parte de la historia general de Sancto Domingo y de su Orden de Predicadores, Madrid, 1584, f. 361r.

17 Eduardo MARTíneZ, Colección diplomática del Real Convento de Santo Domingo de Caleruega, Vergara, 1931, núms. 28 y 29, pp. 34-35; núm. 32, p. 40; Manuel GONZÁLEZ JimÉNEZ, Sancho IV... [ver n. 10], núms. 16, 17 y 59.

18 José Ledo Del PozO, Historia... [ver n. 9], pp. 199 y 341.

19 Años 1266 y 1270 . Hernando del Castillo, Primera parte... [ver n. 16], libro 2, ff. 358r y 360rv. La fundación, en Rita Ríos DE LA Llave, Mujeres de clausura en la Castilla medieval: el monasterio de Santo Domingo de Caleruega, Alcalá de Henares, 2007, pp. 131-134. 
dominico del infante parecía relacionado con la búsqueda de un respaldo clientelar y contrastaba con una acción paterna de horizontes geográficos, relacionales y políticos más amplios. Por otra parte, no necesariamente cabría interpretar la interacción conventual entre los miembros de la familia real como manifestación de acuerdo y colaboración. La acción de doña Violante en Valladolid pudo estar relacionada con su apoyo a los infantes de la Cerda y acaso la de don Sancho en Benavente fuese su respuesta en defensa de su posición dinástica. ¿Reflejaría esto una doble postura política de los dominicos leoneses y castellanos? De haber sido así, Alfonso X le habría puesto punto final al asociar a don Sancho a la fundación de Caleruega, mostrando así que lo reconocía como sucesor.

El infante mantuvo esta línea tras su ruptura con el rey en 1281 y siguió proclamando la filiación sucesoria mediante el impulso a la orden dominica. Ese año pedía al obispo de Ciudad Rodrigo una iglesia para los frailes -previamente impulsados por Alfonso X- presentándose como hijo mayor y heredero. De más amplio alcance fueron sus acciones durante su rebelión. En 1282 tuvieron que ver con Valladolid, lugar donde se desposeyó al rey. Meses antes, don Sancho había escrito a los dominicos de San Pablo y, estando en la ciudad, emitió un importante documento de notables resonancias dinásticas y políticas que lo vinculaba a Fernando III. Presentándose de nuevo como «fiio mayor et heredero» ${ }^{20} \mathrm{de} \mathrm{Al}$ fonso $\mathrm{X}$ y actuando a instancias de su madre, la reina Violante -en este momento aliada suya-, recibía bajo su amparo a todos los conventos de dominicos de Castilla y León. Era una acción novedosa: el rey Sabio no había llegado a privilegiar a la orden de forma tan completa y, si se compara con la protección brindada por Fernando III, don Sancho ampliaba el radio territorial al incluir el reino leonés además de estrechar los lazos con su persona dadas las tensiones sufridas por las comunidades dominicas. Un año después, incluso suplantaba a su padre otorgando a los frailes el mismo privilegio que aquel había concedido en $1276^{21}$.

Subrayemos la singularidad de la inclinación dominica de don Sancho y el peso del reino de León: no hubo acciones similares en pro del franciscanismo en este momento y el infante gozó también del apoyo de los monasterios de Galicia y León, constituidos en hermandad (1283). ¿Podría pensarse que este clientelismo leonés se alimentase de posibles sentimientos secesionistas? Cierto que las

20 Santiago Domínguez SÁnchez, La colección de pergaminos de San Pablo de Valladolid... [ver n. 14], núm. 5, p. 57.

21 Juan LÓPEZ, Tercera... [ver n. 3], libro 1, pp. 283-284; Manuel GONZÁLEZ JiMÉNEZ, Sancho IV... [ver n. 10], núm. 96; Santiago DomínguEZ SÁNCHEZ, La colección de pergaminos de San Pablo de Valladolid... [ver n. 14], núms. 5 y 6, pp. 56-57. 
promociones dominicas que Alfonso X había llevado a cabo en León parecen haber obedecido a objetivos de castellanización y que don Sancho, por su parte, habría capitalizado en beneficio propio la diferencia leonesa para fortalecer su figura política. Su alianza con los dominicos de León contrarrestaría el apoyo que la Orden de Predicadores estaría brindando a su padre ${ }^{22}$, sobre todo en Castilla. De todas formas, no dejó de ser un primer paso hacia la ampliación de su esfera de influencia: tras entablar su vínculo leonés, el que acabase otorgando los importantes privilegios de 1282-1283 a escala general -Castilla y León-indicaría su afán por conseguir el respaldo de toda la orden y posibles objetivos de integración de los dos reinos en torno suyo.

A ello contribuía la conexión entre los conventos y las ciudades. Lo hemos visto en Benavente y es conocida la implicación de los dominicos en la configuración de las estructuras urbanas del siglo XIII ${ }^{23}$. El apoyo a los frailes facilitaba la aproximación personal y propagandística a las ciudades. Sabemos que don Sancho buscó su respaldo y que los concejos acabaron por constituirse también en hermandad en su defensa ${ }^{24}$. Si la exención otorgada a los frailes no dejaba de situar a sus conventos en una esfera por encima del control urbano y en directa conexión con él, podríamos pensar que buscase este doble objetivo: privilegiar a los frailes sin perder el apoyo de las ciudades.

\section{I.2. Perfil dominico del reinado de Sancho IV}

La cultura política del reinado de Sancho IV estuvo signada por la promoción mendicante, sobre todo dominica, y el gran peso de sus establecimientos religiosos, especialmente los conventos de frailes. Desde los inicios del reinado, ello tuvo que ver con dos cuestiones: legitimidad y soberanía.

Sin negar que don Sancho estuviese convencido de su legitimidad, sus primeras acciones pro-dominicas parecen estar manifestando su proclamación pública. Fue así al comenzar dibujando líneas de continuidad dinástica. Ya en 1284 destaca su mayoritaria promoción de establecimientos vinculados a la Corona

22 El respaldo de los mendicantes a Alfonso X: Rita Ríos DE LA LLAVE, The Role of the Mendicant

Orders in the Political Life of Castile and León in the Later 13th Century, en Religion and Political Change in Europe: Past and Present, Pisa, 2003, pp. 21-33.

23 José María Miura Andrades, Frailes, monjas y conventos. Las órdenes mendicantes y la sociedad sevillana bajomedieval, Sevilla, 1998, entre otros trabajos de este autor.

24 José Manuel NieTO SORIA, Sancho IV... [ver n. 1], pp. 38 y 41-42. 
desde Fernando III y el énfasis en los privilegios otorgados por Alfonso X, que se dedicó a confirmar. La llamativa intensidad de concesiones se ciñó a la segunda mitad del año, tras ser coronado en Toledo y Sevilla. El primer documento, otorgado en Sevilla en julio de 1284, beneficiaba a los dominicos toledanos, conectaba sus lugares de coronación y revitalizaba los lazos inicialmente entablados por la reina Berenguela ${ }^{25}$. También favoreció al convento de Burgos, que habría sido hostil a su rebelión. Se trataba del privilegio general de 1283, pero concretando ahora los conventos destinatarios ${ }^{26}$.

Tres casas emblemáticas fueron las únicas receptoras de paquetes de privilegios: San Esteban de Salamanca, Santo Domingo de Madrid y Santo Domingo de Caleruega. El rey proseguía e intensificaba una línea de mercedes iniciada por sus antecesores que favorecía la integración de frailes y monjas en la esfera de los privilegiados y su acercamiento a la Corona. En este juego de vínculos, los gobiernos urbanos quedaban sometidos a los intereses regios. Podríamos pensar que la concesión de mercedes a la Orden de Predicadores redundaba en una afirmación de la autoridad del rey sobre los gobiernos urbanos. Los frailes salmantinos, favorecidos desde Fernando III, recibían un excusado en la ciudad y, además, respondiendo a su queja, el monarca rompía monopolios concejiles al ordenar que se les permitiera introducir en Salamanca el vino que recibían como limosna. Asimismo, reforzaba la protección regia al convento en un contexto de conflictividad social al confirmar un documento de Alfonso X y conceder otro de encomienda en el que garantizaba los privilegios regios y pontificios. Por último, responsabilizaba al concejo de la protección al convento ${ }^{27}$ alineándolo con él y con su política y sometiéndolo a su autoridad.

Las concesiones a Santo Domingo el Real de Madrid constituían otra llamada de atención dinástica que enlazaba con Fernando III y Alfonso X. Don Sancho confirmaba la línea paterna sobre los derechos de propiedad y herencia de las monjas mencionándolo directamente. Porque «viemos una carta» ${ }^{28}$ del rey Sabio, ratificaba la posesión del monasterio de la herencia de una «freyra»y,

25 El papel de la reina, en Eugenio SERRANO RODRÍGUEZ, Toledo y los dominicos en la época medieval. Instituciones, economía, sociedad, Cuenca, 2014, p. 118; María del Mar GRAÑA CID, Berenguela I y Fernando III, promotores de las órdenes mendicantes en Castilla, en Manuel PELÁEZ DEL RosAL (dir.), El franciscanismo: identidad y poder, Córdoba, 2016, pp. 119-141.

26 Mercedes Gaibrois, Historia... [ver n. 3], t. 3, núm. 7, p. V; núm. 28, pp. XVIII-XIX; Francisco García-SERrano, Preachers... [ver n. 3], p. 90.

27 Mercedes GaIBroIS, Historia... [ver n. 3], t. 3, núms. 16-18, pp. XI-XII; núm. 34, p. XXI; Francisco GarcÍA-SERRANO, Preachers... [ver n. 3], p. 60.

28 Mercedes GaibroIs, Historia... [ver n. 3], t. 3, núm. 30, p. XIX. 
además de confirmar rentas, favorecía que las monjas disfrutasen de sus bienes y de las herencias de sus padres durante un tiempo. Recibía al monasterio en su encomienda y confirmaba todos sus privilegios tanto los pontificios como, en una referencia dinástica directa que además lo vinculaba al infante Fernando de la Cerda, los que ya le habían otorgado Fernando III, Alfonso X, su hermano el infante Fernando y él mismo. Referencia dinástica combinada con la personal, pues las monjas habían de rogar por él. El vínculo paterno y dinástico era refrendado asimismo en las concesiones a Santo Domingo de Caleruega mediante la mayoritaria acción confirmatoria de los privilegios de Alfonso $\mathrm{X}^{29}$.

El siguiente paso fue actualizar el privilegio general otorgado en 1283 ampliando sus contenidos y, además, haciendo referencia especial a los dominicos del reino de León. En la nueva versión (1285), el rey afirmaba su voluntad de «levar adelante ${ }^{30}$ a la Orden de Predicadores y hacerle bien y merced, pero sobre todo a los frailes leoneses. No era una concesión de carácter dinástico, pues no establecía obligaciones de ese tipo, sino soberano. Mediante este privilegio, intensificaba el vínculo de los frailes con la Corona y su instrumentalización al servicio de la autoridad de esta sobre los concejos, pero, además, ahora también sobre las autoridades eclesiásticas. El hecho de ser concesiones circunscritas al ámbito de ejercicio soberano, bien fuese en su globalidad o en el reino de León, señala igualmente su función al servicio de la soberanía regia en una clave territorial. Precisamente, la referencia a León invita a pensar en la importancia que su conexión leonesa debió tener, no solo en la fundamentación regia y soberana de Sancho IV, sino en la concepción misma del reino. Por lo demás, se volvía a incidir en la idea de continuidad entre el hijo y el padre al incluir la confirmación de los privilegios otorgados por Alfonso X.

De este modo, el 15 de febrero de 1285 el rey confirmaba a los dominicos todos los privilegios que tenían de don Alfonso y suyos y ordenaba que se les respetasen los pontificios. Hacía especial referencia a la facultad de los frailes para predicar, confesar y enterrar sin que nadie se lo impidiese; a la salvaguarda de sus espacios funerarios y residenciales y de sus servidores, y a su capacidad de tener

29 Mercedes GaIBroIS, Historia... [ver n. 3], t. 3, núms. 30, 31 y 33, pp. XIX-XXI; núm. 37, p. XXIII; Eduardo MARTínEZ, Colección... [ver n. 17], núms. 34-36, pp. 41-42. El marco socioeconómico de ambos monasterios, en Juan Ramón Romero FERnándeZ-PACHECo, Santo Domingo el Real de Madrid. Ordenación económica de un señorío conventual durante la Baja Edad Media (1219-1530), Salamanca, 2008; Rita Ríos DE LA LLAVE, Mujeres... [ver n. 19].

30 Esta expresión se incluye en prácticamente todos los documentos. Por ejemplo: Mercedes GAIBROIS, Historia ... [ver n. 3], t. 3, núm. 51, p. XXXIII. 
libremente cuanto les fuese otorgado para sus necesidades. Situaba bajo su encomienda a todos los conventos de frailes y ordenaba a los obispos y clérigos que no contrariasen sus privilegios ni les hiciesen mal o amparasen a los que abandonasen la orden; también, que se les respetasen todos los excusados. Además, establecía que, en adelante, gozasen de uno en cada villa donde tuviesen convento ${ }^{31}$.

Se trataba de una importante merced general de la que se hicieron copias para los conventos, a veces personalizadas, en otras fechas o con algunos importantes añadidos como la exención de chancillería o el derecho a heredar de los progenitores otorgado por el papa. Aunque habría que valorar esta cuestión más en detalle, da la impresión de que estos añadidos pudieron haber formado parte de otro documento general. De hecho, el 29 de mayo, por hacer bien y merced a los frailes predicadores «de toda nuestra tierra»-aunque más adelante, dado que incluía el documento anterior, afirmaba que «señaladamente», a los del reino de León-, otorgaba exención de portazgo y de tasas de chancillería y la posibilidad de heredar de los progenitores y de otros parientes, tal como había reconocido la Sede Apostólica ${ }^{32}$.

Por lo demás, el monarca seguía enfatizando la conexión dinástica en su relación con las monjas. La cuestión de la exención parecía preocuparle en 1285 . Ordenaba que Santo Domingo de Madrid no pagase portazgo en ningún lugar de sus reinos por lo que llevase, comprase o vendiese para su consumo y necesidades, y permitía que sus ganados se moviesen con libertad por todos sus reinos, «así como los míos mismos» ${ }^{33}$, y los declaraba exentos. En junio otorgaba un documento muy similar a la versión más larga del privilegio dirigido a los frailes de León, con alguna pequeña diferencia. Incidía en la exención de portazgo y de chancillería en todo el reino; reconocía el derecho de herencia de las monjas refrendando la previa concesión pontificia; les confirmaba todos los privilegios de Alfonso $\mathrm{X}$ y suyos y ordenaba que se les guardasen los que tenía de Roma para enterrar y tener libremente cuanto se les diese para sus necesidades; recibía al monasterio en su encomienda y rogaba a los obispos y clérigos de sus reinos que no fuesen contra sus privilegios y que nadie amparase a los frailes que saliesen de la orden; ordenaba que tuviesen y se les guardasen sus apaniaguados y mayordomos excusados tal como figuraba en otros documentos de las monjas; por último, que nadie hiciese tuerto ni maltratase a las dueñas, freiras y frailes del monasterio ni

31 Raquel del Carmen Fernández Ruiz, Colección... [ver n. 10], núms. 14 y 15, pp. 52-54; Manuel RisCO, Iglesia de León y monasterios antiguos y modernos de la misma ciudad, Madrid, 1792, pp. 173-177.

32 Mercedes Gaibrois, Historia... [ver n. 3], t. 3, núm. 78, p. L; Raquel del Carmen FERnández RUIZ, Colección... [ver n. 10], núm. 16, pp. 54-55.

33 Mercedes GaIBROIS, Historia... [ver n. 3], t. 3, núm. 80, p. LI. 
a quienes les servían. Aunque menos intensa, su actuación en Santo Domingo de Caleruega supuso la confirmación de rentas otorgadas por su padre y la concesión de un documento sobre los ganados muy similar al de Madrid ${ }^{34}$.

Estas disposiciones reflejan el clima de crispación provocado por la pastoral de los frailes ${ }^{35} \mathrm{y}$ por la presencia misma de un establecimiento dominico dados sus derechos, sobre todo en materia de enterramiento, así como sus crecientes exenciones. Pero también, insisto, el vínculo directo que don Sancho trababa entre él como titular de la Corona y la Orden de Predicadores, lo cual suponía enfatizar la continuidad dinástica y contribuir a la construcción pública de una imagen de legitimidad. Igualmente, era manifestación de su acción soberana en toda la extensión de sus reinos, por encima de las autoridades eclesiásticas y locales. Ello reforzaba la autoridad regia y contribuía a crear conciencia de unidad territorial o, cuando menos, de identidad común.

El énfasis en el área leonesa bien pudo ser fruto de una acción de recompensa al apoyo prestado por los frailes leoneses y la forma de garantizar su continuidad. Desde luego, parecen haber afianzado un vínculo que después daría más frutos en las esferas de la alta política. En 1286, dos dominicos accedían a las dos diócesis más importantes del reino de León: fray Pedro Fechor, del convento de San Esteban, al obispado de Salamanca ${ }^{36}$, y fray Rodrigo González de León a la archidiócesis compostelana; este último había sido provincial de Hispania y el rey afirmaba que «siempre fue y es a mío servicio» ${ }^{37}$. Ello sin olvidar la cuestión territorial: don Sancho seguía haciéndose fuerte en León, respaldando a su vez, de algún modo, la singularidad del reino mientras, por otro lado, construía una noción soberana más amplia mediante las ya mencionadas concesiones generales. No conocemos la fecha, pero tuvo que ser después de tomar posesión de su sede en 1290 cuando el arzobispo fray Rodrigo González promocionó las peregrinaciones y limosnas al convento de Santo Domingo de Benavente ${ }^{38}$. Este tipo de acciones contribuían a consolidar la proyección pública del rey: el engrandecimiento del convento por él fundado, llevado a cabo por un obispo igualmente promocionado por él, sin duda iban en esa línea y otorgaban a la villa de Benavente un carácter más central, incidiendo así en la jerarquización de los núcleos urbanos leoneses. Por lo demás,

34 Mercedes Gaibrois, Historia... [ver n. 3], t. 3, núms. 80 y 81, pp. LI-LII; núm. 84, pp. LIV-LV; Eduardo MARTÍNEZ, Colección... [ver n. 17], núms. 37 y 38, pp. 43-45.

35 Alicia ÁLVAREZ RODRÍGUEZ, Los frailes y la «cura animarum» como actividad conflictiva en Zamora, Toro y Benavente durante la Baja Edad Media, en Edad Media. Revista de Historia, 19 (2018), p. 228, n. 31.

36 Bernardo Dorado, Compendio histórico de la ciudad de Salamanca, Salamanca, s.a., p. 235.

37 Mercedes Gaibrois, Historia ... [ver n. 3], t. 1, p. 121, n. 1.

38 Raquel del Carmen FERnáNDEZ RuIZ, Colección... [ver n. 10], núm. 33, pp. 70-71. 
la estrecha relación del rey con fray Munio debió beneficiarlo de los contactos que este religioso habría trabado en el área leonesa durante su vicariato.

Esta relación parece signar algunas destacadas acciones pro-dominicas de Sancho IV, sobre todo las de carácter más amplio. No parece casualidad que el primer privilegio general que otorgó en 1283 coincidiese con fray Munio ${ }^{39}$ al frente de la provincia dominica de Hispania, función que ejercía desde su elección en 1281 -año de ruptura entre don Sancho y su padre-. También resulta llamativa la coincidencia entre las nuevas concesiones generales de 1285 y la elección del fraile como maestro general de la Orden de Predicadores. Sabemos que fue un general innovador. Además de atribuírsele la fundación de la Tercera Orden dominica, cabe subrayar el paquete de privilegios que le otorgó Honorio IV precisamente entre octubre de 1285 y enero de 1286: en ellos se introducían cambios litúrgicos y se trataban aspectos como la expansión fundacional, la independencia de los obispos y la confirmación de sus privilegios ${ }^{40}$. Las acciones de Sancho IV, alineadas con las pontificias, lo sintonizaban con la Sede Apostólica cuando luchaba por solucionar sus problemas de ilegitimidad ${ }^{41}$.

Tras los dos intensos primeros años del reinado, a partir de 1286 descendió el nivel de concesiones, pero el rey siguió beneficiando de forma especial a la orden en el reino de León y, además de mantener vínculos, amplió presencias. A San Esteban de Salamanca le confirmó lo concedido por su padre, posible señal de que no se respetaba, pero también de la importancia que seguía otorgando a la filiación conventual. También se vinculó a establecimientos nuevos: tras favorecer a Santa María de las Dueñas de Zamora y facultar la ampliación de la jurisdicción dominica, intensificó presencias en la ciudad ${ }^{42}$. Por lo demás, mantuvo su línea

39 Mercedes Gaibrois, Fray Munio de Zamora, en Abhandlungen aus dem Gebiete der mittleren und neueren Geschichte und ibrer Hilfswissenschaften. Eine Festgabe zum siebzigsten Geburtstag Geh. Rat Prof. Dr. Heinrich Finke, Münster, 1925, pp. 135-154.

40 Santiago Domínguez SÁNCHEZ, La colección de pergaminos de San Ildefonso de Toro (1127-1589): un vademécum para la diplomática pontificia, León, 2019, núms. 4-5, pp. 65-68; núm. 7, pp. 69-72.

41 Se han resaltado los años 1284 y 1285. José Manuel NiETO SORIA, Sancho IV... [ver n. 1], p. 49.

42 En 1287 intervenía para que el obispo de Zamora don Suero aceptase que las monjas abandonasen su jurisdicción para someterse a los dominicos. Mercedes GAIBROIS, Historia ... [ver n. 3], t. 1, p. 142, n. 3; t. 2, p. 58, n. 1; Melchor ZATARAÍN FERNÁNDEZ, Apuntes y noticias curiosas para formalizar la bistoria eclesiástica de Zamora y su diócesis, Zamora, 1898, pp. 90-91; Hernando del Castillo, Segunda parte... [ver n. 4], f. 56rv; Peter Linehan, La Iglesia... [ver n. 1], p. 201; Las dueñas de Zamora. Secretos, estupro y poderes en la Iglesia española del siglo XIII, Barcelona, 2000, pp. 112-114. Alicia ÁLVAREZ RoDRíGUEZ, Los concejos de Zamora y Benavente y su relación con los conventos de la Orden de Predicadores durante los siglos XIII-XV, en Studia Historica. Historia Medieval, 33 (2015), p. 279, n. 66; Francisco ZuRDO, Zamora dominicana, Zamora, 1994, p. 55. 
de privilegios a Santo Domingo de Caleruega en lo que parece haber constituido el vínculo más persistente de su reinado: confirmo privilegios y lo hizo partícipe de sus concesiones generales ${ }^{43}$.

La gran novedad de los últimos 80 fue la intensificación de sus acciones en Castilla, sobre todo después de que en diciembre de 1288 situase bajo su protección a los dominicos castellanos. Con ello, inició y afianzó la inclusión de conventos en su órbita directa además de equilibrar el vínculo leonés dado que no abandonó sus vínculos conventuales anteriores ${ }^{44}$. En 1289, sus concesiones habrían alcanzado a los dominicos de todos sus reinos ${ }^{45}$, lo cual coincidía con el inicio de la etapa culmen del reinado ${ }^{46}$. En línea similar estarían las concesiones a los dominicos de Santa Cruz de Segovia en 1290; don Sancho hacía una de las pocas referencias dinásticas directas en relación con este convento, fundado por santo Domingo. En la confirmación de un privilegio de Alfonso X pedía a los frailes que rogasen por el alma de su padre y las vidas de él, su esposa e hijos. En marzo concedía a los dominicos de Castilla la exención de portazgo ya otorgada a los de León para hacer bien y merced a los frailes predicadores «de toda nuestra tierra ${ }^{47}$, concesión que asimismo otorgaba a conventos concretos ${ }^{48}$.

Las acciones regias de mayor radio territorial coincidían de nuevo con el envío de documentos del papa al general fray Munio. Entre 1288 y 1290, Nicolás IV trataba sobre la integridad de los efectivos de la orden y su sometimiento disciplinar, aunque destaca su acogida bajo la jurisdicción pontificia sin mediaciones y la prohibición de que los dominicos fuesen promovidos al episcopado sin licencia ${ }^{49}$. Pese a que estas dos últimas cuestiones tanto podían favorecer la intensificación

43 Eduardo Martínez, Colección... [ver n. 17], núms. 39-46, pp. 45-50.

44 César González Mínguez, Itinerario y regesta de Fernando IV de Castilla (1295-1312), Bilbao, 2015, 1299, núm. 84, p. 195; Santiago DOMíNGUEZ SáNCHEZ, La colección de pergaminos de San Pablo de Valladolid... [ver n. 14], núm. 8, p. 58; El convento dominico de San Pablo de Palencia... [ver n. 13], núm. 24, pp. 100-101; Mercedes GaIBROIS, Historia ... [ver n. 3], t. 1, pp. 94, n. 1; 210, n. 1.

45 Ese año, cuatro frailes del convento de Vitoria hacían valer ante las autoridades de la villa los privilegios de Sancho IV. Ernesto García FERNáNDEZ, Dominicos y franciscanos en el País Vasco (siglos XIII-XV), en VI Semana de Estudios Medievales, Logroño, 1996, p. 215.

46 Fernando GUTIÉRREZ BAÑos, Las empresas artísticas de Sancho IV el Bravo, Burgos, 1997, p. 26.

47 Mercedes GaIBrois, Historia... [ver n. 3], t. 3, núm. 296, p. CLXXXV.

48 Mercedes GaIBroIs, Historia... [ver n. 3], t. 3, núm. 293, p. CLXXXII; núm. 296, pp. CLXXXVCLXXXVI; núm. 327, p. CCVIII-CCIX; Francisco GARCÍA-SERRANO, Preachers... [ver n. 3], p. 70, n. 270.

49 Santiago Domínguez SÁncheZ, La colección de pergaminos de San Pablo de Valladolid... [ver n. 14], núm. 9, pp. 58-60; núm. 10, pp. 60-61; La colección de pergaminos de San Ildefonso de Toro... [ver n. 40], núms. 8-11, pp. 72-79; Raquel del Carmen FERNÁNDEZ RuIZ, Colección... [ver n. 10], núm. 18 , p. 57. 
de la autoridad del rey sobre la orden como limitarla, en 1290 don Sancho gozaba de gran ascendiente. Prueba de ello sería su solicitud de celebrar capítulo general en San Pablo de Palencia en 1291, hecho significativo porque fue el único que se llevó a cabo en Castilla en el siglo XIII ${ }^{50}$. Ello denota igualmente el peso alcanzado por Castilla en la política dominica del rey. Este capítulo otorgó licencia para fundar tres nuevos conventos, entre ellos uno en Oviedo a petición de don Sancho ${ }^{51}$. Los cronistas destacaron su inclinación por los frailes afirmando que asistió al capítulo «aviendo muy grand placer porque viera y muchos frayles ayuntados» ${ }^{52}$. A comienzos de los 90 culminaba la alianza rey-orden. También la falsificación de la bula legitimadora del matrimonio regio habría sido promovida entonces (1292) por un dominico que se presentaba en la curia como «procurador del rey de Castilla $\gg^{53}$ y confiaba en alcanzar un obispado. En años siguientes se percibe cierto equilibrio entre los establecimientos leoneses y castellanos ${ }^{54}$.

La elección de fray Munio de Zamora como obispo de Palencia en 1294 culminaba la fusión de los vínculos dominicos en León y Castilla. El acto se celebró en el convento de San Pablo de Palencia en presencia de los reyes y una amplia representación de frailes encabezados por el prior de Hispania. El servicio de fray Munio a Sancho IV era reconocido por éste en el documento de confirmación de los privilegios del obispo y obispado de Palencia al afirmar «nos fizo muchos seruiçios et faze ${ }^{55}$. El hecho dibuja un interesante panorama de conexiones. Fray Munio había profesado en el convento de Palencia y es posible que Sancho IV contribuyese a su edificación. Allí estaban representados todos los dominicos hispanos respaldando la elección episcopal, la ceremonia y la presidencia regia. Ello

50 Santiago Domínguez SánCHeZ, El convento dominico de San Pablo de Palencia... [ver n. 13], núm. 27, pp. 113-117. En la península solo hubo otro en Barcelona (1261). Francisco GARCía-SERRANO, Preachers... [ver n. 3], p. 72, n. 297.

51 Pilar García Cuetos, El convento dominico de Nuestra Señora del Rosario de Oviedo. Historia y arquitectura, Oviedo, 2001, p. 20.

52 Crónicas de los reyes de Castilla. Desde don Alfonso el Sabio hasta los católicos don Fernando y doña Isabel, Madrid, 1953, t. 1, Crónica del rey don Sancho el Bravo, p. 85.

53 Salustiano Moreta Velayos, Notas... [ver n. 5]; Peter Linehan, La Iglesia... [ver n. 1], p. 196.

54 El rey defendía a los frailes en Ciudad Rodrigo o Toledo, confirmaba privilegios de larga tradición y mantenía la conexión con las monjas de Madrid y Caleruega. Manuel $M^{a}$ DE LOS HoYOS, Material inédito... [ver n. 10], t. 2, pp. 266, 259, y 261; Mercedes GAIBROIS, Historia... [ver n. 3], t. 3, núm. 485, p. CCCXXX; núm. 335, pp. CCXIII-CCXIV; núm. 591, p. CDIV; t. 2, p. 231, n. 1; núm. 327, pp. CCVIII-CCIX; César GONZÁLEZ MíNGUEZ, Itinerario... [ver n. 44], 1299, núm. 51, p. 128.

55 Santiago Domínguez Sánchez, El convento dominico de San Pablo de Palencia... [ver n. 13], núms. 28 y 29, pp. 118-122. En otro reconocía «nos a fecho mucho seruiçio a nos et a la reyna». Peter LINEHAN, Las dueñas... [ver n. 42], p. 135, n. 6. 
sin olvidar que el acto culminaba la protección dispensada por el rey al controvertido fray Munio ${ }^{56}$.

La ceremonia palentina invita a reflexionar sobre la cuestión territorial y soberana en relación con la unión de León y Castilla. Si Alfonso X había intensificado el vínculo entre la Corona y los dominicos en León dando muestras de lo que a todas luces cabría calificar como un afán por castellanizar el reino leonés, las acciones de don Sancho parecen evidenciar el objetivo de integrar sus reinos enfatizando el protagonismo leonés. Acaso podría interpretarse en esta línea el que, tras reforzar los privilegios de los dominicos leoneses, se dedicase a difundir entre conventos castellanos el mismo documento -¿quizá también el hecho de no eliminar la referencia leonesa?-. La posterior concesión de un privilegio general a Castilla sería el siguiente paso lógico. Su culminación se manifestaría en esta ceremonia, con todos los dominicos de la provincia de Hispania reunidos en torno al rey, como si se estuviese poniendo de manifiesto una especie de «nacionalismo ${ }^{57}$ castellano-leonés en clave dominica y con ciertas dosis de autosuficiencia, quizá sobre todo en relación con el papado, máxime por parte de una orden que dependía directamente del mismo pero que tan activa y estrechamente se vinculaba a la Corona en la persona del rey y, sobre todo, teniendo en cuenta la azarosa relación de fray Munio con la Sede Apostólica.

Otros privilegios, algunos en fechas imprecisas, subrayaban la continuidad entre Sancho IV y Alfonso X. Don Sancho cumplió su compromiso con su padre y promovió las obras de la iglesia de Santo Domingo de Caleruega. A San Pablo de Burgos le otorgó una plaza ayudando a su edificación como ya hizo el rey Sabio, y debió continuar su obra edilicia en Santo Domingo de León ${ }^{58}$.

Identidad nacional, dinastía y autoridad del rey habían sido cuestiones ya planteadas por Alfonso X en su relación con los mendicantes, especialmente la Orden de Predicadores. Pero con Sancho IV, dado el contexto social y la necesidad política de visibilizar fundamentos de legitimidad, alcanzaban un carácter casi privativo ofreciendo una imagen de notoria cohesión en torno a la Corona en clave dominica. En este sentido, su reinado fortaleció una alianza fundada en el servicio y el privilegio y vinculó estos conceptos a la soberanía y geopolítica del reino.

56 Peter Linehan, Las dueñas... [ver n. 42], pp. 127-148.

57 Sobre el «incipiente nacionalismo castellano» en relación con la orden dominica: Santiago Aguadé Nieto, Alfonso X y las órdenes mendicantes, en Saxonia Franciscana, 10 (1998), pp. 288ss.

58 José Antonio Casillas García, El convento de San Pablo de Burgos. Historia y arte, Salamanca; Burgos, 2003, p. 125, n. 355; Juan LóPEZ, Tercera ... [ver n. 3], libro 1, pp. 165 y 274; Manuel RIsCO, Iglesia... [ver n. 31], p. 173. 


\section{DoÑa MARÍA, LOS FRAILES Y LA AUTORIDAD REGINAL}

La promoción dominica de María de Molina ${ }^{59}$ facilita la comprensión de su papel político y, a la vez, se perfila como uno de los instrumentos que contribuyeron a construirlo y fundamentarlo. Una dimensión política inseparable de la devoción.

\section{II.1. Entre socia del rey y figura política independiente}

Su fase como consorte manifiesta la comunión del vínculo matrimonial ${ }^{60}$. Coincidió con Sancho IV en: la promoción dominica, preferencia por frailes, fecha de inicio, 1284, recién ceñida la corona; dimensión señorial, y secuencia León-Castilla. Se desprende una imagen de coordinación e identificación de la pareja en formas y objetivos, algo favorecido por la necesaria defensa de su legitimidad.

A finales de 1284, la reina daba origen al convento de Santa María de Toro, después conocido como San Ildefonso, al comprar unas casas muy cerca de su residencia, en la que se denominaría «calle de la Reina». En 1285 las donó a los dominicos y en 1290 ya funcionaba la comunidad ${ }^{61}$. Acaso desde 1286 actuase en otra población reginal, Valladolid, impulsando el proceso iniciado en 1276 por la reina Violante ${ }^{62}$, que había sido desposeída de la ciudad por don Sancho. La acción de doña María fue una reedificación: le confirió carácter personal al optar por construir un convento magnífico denominado San Pablo en el lugar donde los frailes residían con gran estrechez ${ }^{63}$. Sustitución y reedificación podrían es-

59 Una valoración general de su promoción religiosa, en María del Mar GRAÑa CID, The Mendicant Policies of the Queens of Castile in the 13th Century: the Implantation of Convents, en Nikolas JASPERT y Imke JusT (eds.), Queens, Princesses and Mendicants: Close Relations in a European Perspective, Zurich, 2019, pp. 65-83. Sobre doña María, pp. 77-81.

60 Diana Pelaz FloRES, «Reynante(s) en vno». Fundamentación teórica del poder de la pareja regia en la Corona de Castilla durante la Baja Edad Media, en Anuario de Estudios Medievales, 48/2 (2018), pp. 845-869.

61 Juan López, Tercera... [ver n. 3], libro 1, pp. 302-303; Rafael FloRANES y ENCINAS, Memorias para la bistoria de la ciudad y tierra de Toro, Zamora, 1994, pp. 97-98; Santiago DOMÍNGUEZ SÁNCHEZ, La colección de pergaminos de San Ildefonso de Toro... [ver n. 40], núm. 6, pp. 68-69; núm. 12, pp. 79-80; núm. 13, pp. 80-81; núm. 14, pp. 82-83.

62 La reina ordenó al concejo que cediese un solar respondiendo a la petición de los frailes. Adeline RuCQuOI, Valladolid en la Edad Media, t. 1, Génesis de un poder, Valladolid, 1987, pp. 198-199.

63 Manuel José de Medrano, Historia de la provincia de España de la Orden de Predicadores. Segunda parte, t. 1, libro 2, Madrid, 1729, p. 311. 
tar indicando la novedad del modelo político y no podemos dejar de pensar en la necesidad de una acción coordinada de los reyes en este sentido. En 1290 se inician las noticias documentadas ${ }^{64}$. El impulso fundacional de la reina la situaba en paralelo con el rey: coincidía en cronología con el desarrollo de la acción de don Sancho en Castilla y posicionaba a los dominicos por encima de los concejos: el de Valladolid hubo de someterse a los intereses de los frailes, aun contrariando los suyos, porque el respaldo de la reina los habría tornado «audaces» en su implantación urbana ${ }^{65}$. Además, en este convento fue enterrado el infante don Alfonso en $1291^{66}$.

María de Molina, sintonizada con Sancho IV, servía a los intereses de la Corona compartiendo objetivos y formas de actuación en los mismos enclaves preferentes. No obstante, ofreció un perfil propio como «plena fundadora». Se ha afirmado que el convento de Toro fue el único directa y enteramente fundado por la monarquía en el siglo XIII ${ }^{67}$, pues la reina aportó los bienes básicos, costeó la construcción de las dependencias principales y actuó sin intermediarios. Algo similar ocurrió en Valladolid y por eso fue considerada «fundadora» del convento de San Pablo en sentido pleno ${ }^{68}$, pese a que la promotora de la implantación hubiese sido la reina Violante.

Otra esfera de equiparación diferenciada con el rey fue la concesión de limosnas. Ambos pudieron actuar en pareja, pero ella tuvo un perfil independiente y más intenso. Destacó su interés por la vicaría leonesa en la década de 1290, como si en este ámbito complementase la por entonces mayor atención del rey hacia Castilla. En 1294 beneficiaba a los dominicos de Toro, León y Benavente recompensando las oraciones que les había pedido cuando don Sancho estaba en la campaña de Tarifa, y también favorecía a los dominicos de Santiago ${ }^{69}$. Estos datos, escasos y circunscritos en su cronología, muestran una forma de implicación propia: la petición de oraciones por el éxito de las empresas de la Corona y

64 En 1290, doña María otorgaba 4.000 maravedíes anuales en el portazgo de Valladolid para la ya iniciada fábrica de la iglesia y el claustro. Santiago DomínguEZ SÁNCHEZ, La colección de pergaminos de San Pablo de Valladolid... [ver n. 14], núm. 11, pp. 61-62; núm. 12, p. 62; Francisco GarCÍA-SERRANO, Preachers... [ver n. 3], p. 64.

65 Santiago Domínguez SáncheZ, La colección de pergaminos de San Pablo de Valladolid... [ver n. 14], núm. 14, p. 63; Francisco GARCÍA-SERRANO, Preachers... [ver n. 3], pp. 64-65.

66 Ricardo del ARCO y Garay, Sepulcros de la Casa real de Castilla, Madrid, 1954, p. 271.

67 Francisco García-SERRANO, Preachers... [ver n. 3], p. 71.

68 Manuel José de Medrano, Historia... [ver n. 63], libro 2, p. 312.

69 Asunción López Dapena, Cuentas y gastos (1292-1294) del rey D. Sancho IV el Bravo (1284-1295), Córdoba, 1984, pp. 435; 447; 449; 500; 585; 595 y 600; Mercedes GAIBROIS, Historia ... [ver n. 3], t. 1, pp. XLVIII, L, LXXVIII y CVII; t. 2, p. 180. 
la protección del rey. El impulso reginal activaba esta importante función política de los frailes y lo hacía en el sector leonés, tradicionalmente más identificado con don Sancho.

La reina participaba de forma plena en la cultura política del reinado promocionando frailes y conventos. Aunque hallamos paralelos con la actuación de doña Violante en tiempos de Alfonso X, la de doña María parece haber contribuido a construirla como sujeto político. Su especial implicación fundacional generaba un vínculo personal potente con sus conventos en el espacio del señorío reginal. De este modo, las fundaciones conventuales concretaban su poder, lo hacían visible y fundamentaban su autoridad. Esta notoria singularización de su figura y de su capacidad de poder la equiparaban a don Sancho, que desde sus tiempos de infante había singularizado y afirmado su figura política mediante sus acciones conventuales y que, siendo rey, al otorgar protección y privilegios a los conventos, creaba lazos de identificación estrecha con su persona y redes de servicio. Sin duda también, esta forma de fundar situaba a la reina en una peculiar posición de liderazgo respecto a la Orden de Predicadores, con todo lo que esto podía representar en el ámbito de los vínculos de servicio. Por otra parte, el hecho de que las acciones de los reyes pudieran tener efectos similares, tanto en la creación de redes de servicio como, por ejemplo, en lo que atañe a la relación entre frailes y concejos, señala igualmente pautas de equiparación además de indicar que compartirían unos mismos objetivos. No se escapa, además, que la reina, al pedir oraciones y repartir limosnas entre los conventos del reino de León, sobre todo aquellos más relacionados con la pareja, afianzaba la red clientelar iniciada por don Sancho, así como su propia integración en la misma. Incluso, habría sido muy consciente de la importancia de ampliar la identificación entre los conventos y las personas regias a otros miembros de la familia pero enfatizando el peso de la reina, como plasmaría el entierro del infante Alfonso en San Pablo de Valladolid.

Todo esto sería indicativo de un modelo de monarquía en el que la reina era pieza clave en el ejercicio político. Y no solo por actuar como «socia» del rey ${ }^{70}$, sino porque, más allá de una labor de colaboración o de complementariedad, podría pensarse en una dimensión de equiparación. Desde la perspectiva que seguimos, los reyes no actuaban como una pareja complementaria, sino como dos sujetos políticos trabajando en sintonía y de formas similares, si bien con las lógicas diferencias que imponía la esfera de acción de cada uno. Ello se asentaba

70 Paulette Lynn PePIn, María de Molina, Queen and Regent. Life and Rule in Castile-León, 12591321, London, 2016, p. 45; Diana PELAZ FlORES, «Reynante(s)...» [ver n. 60]. 
sobre la singularización de la reina como agente soberano con su propia capacidad de poder. De ello informa su actividad conventual, que sería a un tiempo la concreción y el fundamento simbólico de estos planteamientos, como también lo fue en su momento para el infante Sancho en su calidad de aspirante al trono. No podemos indicar aquí cómo se gestionó en el seno de la pareja regia, aunque resulta muy significativo el papel de consejera permanente que asume doña María en la Crónica de Sancho IV. Nos limitamos a señalarlo sin dejar de tener en cuenta, lógicamente, la distancia entre los hechos y sus representaciones. En cualquier caso, intuimos un papel activo continuo de la reina en la promoción dominica. Así en la eclosión de los vínculos en Palencia en los 90, tanto al celebrarse el capítulo general como en la promoción episcopal de fray Munio dada la ascendencia palentina de la reina. También, por lo mismo, su parentesco con dominicos tan destacados como San Telmo por línea materna y su vinculación directa al referente dinástico del primer rey pro-dominico, Fernando III, su abuelo por línea paterna, vínculos que su labor de promoción dominica manifestaba implícitamente y que podían ser instrumentos positivos en la lucha por el reconocimiento de legitimidad.

¿Qué decir de la actuación de María de Molina en los momentos en que tuvo mayor peso político formal, durante las minorías de su hijo y nieto? La Orden de Predicadores siguió gozando de la preferencia de la Corona. La reina no fue la única tutora y sería arriesgado afirmar que las acciones de los reyes niños siguiesen sus directrices en todo. No obstante, apreciamos puntos comunes.

Durante la minoría de Fernando IV (1295-1301), las concesiones a los dominicos se redujeron drásticamente, se retrasaron y tendieron al equilibrio entre frailes y monjas. En los agitados primeros años debió verse más necesario conseguir el apoyo de las ciudades ${ }^{71}$, de ahí que no se siguiese la activa política de captación clientelar de frailes y conventos por la vía del privilegio característica de los inicios de Sancho IV. Otro hecho determinante sería que el rey fuese considerado hijo ilegítimo hasta 1301.

Antes de esa fecha se señalaron líneas de continuidad con don Sancho confirmando sus privilegios a los monasterios femeninos, principalmente Santo Domingo de Madrid y después Caleruega ${ }^{72}$. En este caso, podría hablarse de filiación monástica, no tanto conventual, y del simbolismo dinástico asociado a las

71 Se han subrayado los esfuerzos de la reina en este sentido. Enrique FLÓREZ, Memorias de las reinas católicas, t. 2, Valladolid, 2002, p. 553.

72 César GonZÁlez MíngueZ, Itinerario... [ver n. 44], 1295, núm. 97, p. 51; 1299, núms. 18 y 21, pp. 118-119; núm. 51, p. 128; 1300, núm. 33, p. 149. 
monjas. Hubo que esperar a 1297 para documentar a los frailes: en respuesta a su petición, don Fernando confirmaba el privilegio por el que su padre confirmaba los otorgados por Alfonso $\mathrm{X}$ y los suyos, pero se limitaba a pedir que rogasen a Dios por él, sin referencias dinásticas, aunque apuntalaba su soberanía por tratarse de los dominicos «de toda nuestra tierra». Las confirmaciones generales a los frailes se incrementaron en 1301, en los meses previos a su legitimación, afirmando la alianza entre la Orden de Predicadores y la Corona. Pudo repercutir también en ello la división de la provincia de Hispania en 1298. Entre las escasas novedades, resulta significativo que don Fernando favoreciese a Santo Domingo de Benavente otorgándole un excusado en Zamora, como si estuviese revitalizando los vínculos clientelares trabados por su padre ${ }^{73}$.

Tras ser legitimado por la Sede Apostólica, el rey siguió confirmando algún privilegio general ${ }^{74}$. En los meses finales de 1301 las referencias dinásticas fueron más evidentes y se vincularon sobre todo a las monjas. Don Fernando hacía recaer la representatividad dinástica en Santo Domingo de Madrid, lo cual le permitía remontarse al rey Santo. En noviembre declaraba haber visto una carta de Alfonso X en la que constaba que Fernando III y la reina Beatriz tuvieron al monasterio en su encomienda, que tras su muerte la había establecido el rey Sabio y que ahora lo hacía él ${ }^{75}$. Cabría pensar que estas ideas estaban presentes desde los inicios del reinado en las concesiones a Madrid, pero era ahora cuando podían manifestarse plenamente, algo indicativo de que el vínculo dominico no sería tanto una fuente de legitimación cuanto un instrumento de manifestación simbólica de legitimidad.

No dudamos de la influencia de doña María ni de que gozó del respaldo de la Orden de Predicadores durante estos años, porque, como veremos, esto se desprende indirectamente de su primer testamento, pero las noticias son muy parcas. Mantuvo la identificación familiar con los conventos subrayando simbólicamente su papel como reina madre y titular señorial al enterrar a otro de sus hijos, don Enrique, en su convento de Toro (1299). Además, hay indicios del peso de su círculo cortesano en sus conexiones dominicas y políticas. Así lo indicaría el papel

73 Francisco Zurdo, Zamora... [ver n. 42], p. 55; Raquel del Carmen FERnÁNDEZ RUIZ, Colección... [ver n. 10], núm. 26, pp. 64-65; Manuel $M^{\mathrm{a}}$ DE LOS HoYOS, Material inédito... [ver n. 10], t. 2, p. 39; Santiago Domínguez SÁNCHEZ, El convento dominico de San Pablo de Palencia... [ver n. 13], p. 31.

74 César GONZÁlez MínguEZ, Itinerario... [ver n. 44], 1301, núm. 2, p. 169; núm. 24, p. 176; núm. 32, p. 179; núm. 52, p. 185; núm. 76, p. 192; núm. 84, p. 195; Raquel del Carmen FERNÁNDEZ RUIZ, Colección... [ver n. 10], núm. 32, pp. 69-70.

75 César GonZÁlez MíngueZ, Itinerario... [ver n. 44], 1301, núm. 79, p. 193. 
activo de sus confesores, caso de fray Domingo de Robledo en la resolución del problema de Navarra. Para los cronistas dominicos, alguna de las confirmaciones generales otorgadas a la orden en 1301 fue muestra de gratitud a los servicios prestados por este fraile a la Corona. Por lo demás, sus confesores, además de los frailes de San Pablo de Valladolid, fueron importantes prelados dominicos como el obispo de Salamanca y el arzobispo de Santiago ${ }^{76}$. ¿Acaso se intensificó el vínculo dominico cortesano durante esta minoría?

El hecho de que Alfonso XI mantuviese relaciones estrechas con la Orden de Predicadores durante la suya (1312-1321) sería indicio de la progresión del dominicanismo cortesano. Bautizado por un dominico, debió tener por confesor a fray Alonso de Zamora, que además pudo ser su maestro y obtuvo la mitra de Sigüenza. Sin embargo, en la concesión de privilegios se mantuvo la tónica anterior: visible preferencia dominica, pero reducido número de documentos e inclinación más temprana por Santo Domingo de Madrid (1314) ${ }^{77}$, aunque las confirmaciones se otorgaron de forma escalonada, entre 1315 y 1321. De nuevo se percibe una actitud prudente, quizá por la necesidad de seguir contando con el apoyo de las ciudades y porque la conflictividad social en torno a los establecimientos religiosos debía ser mayor.

La gran novedad de estos años fue la plena singularización política de doña María. Como ya hiciese con su hijo, participó con su nieto en algunas confirmaciones de privilegios o en el refrendo de sus propias acciones, como la edificación del monasterio de Toro $(1316)^{78}$. Pero, sobre todo, rebasó sus espacios señoriales para beneficiar por su cuenta a conventos masculinos de especial relevancia y pareció asumir el comportamiento de los reyes integrándose en la cadena de los titulares de la Corona. En 1315 favoreció a San Pablo de Burgos, fundación promovida por Alfonso X, Sancho IV y Fernando IV, donando 4.000 maravedíes para finalizar el dormitorio iniciado por su hijo en 1309. En 1318 otorgaba un

76 Luis Alonso Getino, Dominicos españoles confesores de reyes, Madrid, 1917, p. 32. Como es sabido, las actuaciones diplomáticas de los frailes se remontan a los reinados anteriores. Un ejemplo en el de Sancho IV: Mercedes GaIBroIS, Historia... [ver n. 3], t. 1, p. 14.

77 Luis Alonso Getino, Dominicos... [ver n. 76], pp. 33-34; Esther GonZÁlez Crespo, Colección documental de Alfonso XI. Diplomas reales conservados en el Archivo Histórico Nacional, Sección de Clero. Pergaminos, Madrid, 1985, núm. 4, pp. 41-42; núm. 47, pp. 86-91; núm. 76, p. 124; núm. 16, pp. 49-50; núm. 63, p. 108; Francisco GARCÍA-SERRANO, Preachers... [ver n. 3], p. 90, n. 353.

78 Pascual Galindo Romeo, Catálogo del Archivo del Monasterio de Sancti Spiritus de Toro, en Archivos Leoneses, 30 (1976), núm. 5, p. 210; Mercedes PÉREZ VIDAL, Sancti Spiritus de Toro: arquitectura y patronazgo femenino, en Liño. Revista Anual de Historia del Arte, 14 (2008), p. 11. 
gran huerto a San Pablo de Valladolid ${ }^{79}$. Frente a las acciones confirmatorias de su nieto, la reina asumía todo el protagonismo en la promoción dominica.

Las crónicas la presentan pidiendo apoyo precisamente a estos conventos a fin de solventar las dificultades de la minoría. Para algunos autores, el respaldo de San Pablo de Burgos explicaría la posterior generosidad de la reina, aunque el vínculo pudo darse en sentido inverso. También el prior de San Pablo de Valladolid habría trabajado para establecer el «sosiego público» y aliviar los cuidados de doña María. Además, la relación con los dominicos parece haber sido algo cotidiano y cercano en la gestión de diversos asuntos ${ }^{80}$. ¿Cabría pensar en una intensificación de sus relaciones con la orden en estos años?, ¿̇más fluidez en los contactos quizá? Habría que indagar en ello.

Prudencia en la concesión de privilegios y opción inicial por las monjas, sobre todo las de Madrid, serían características de estas minorías y probablemente estuvieron inspiradas por doña María en un posible afán de subrayar el simbolismo dinástico. Resulta significativo que Fernando IV y Alfonso XI siguiesen apoyando a la Orden de Predicadores tras su mayoría de edad y que coincidiesen en la diversificación de sus contactos, pero, sobre todo, en su preferencia por los frailes. Inclinación que fomentaba la dimensión clientelar de servicio activo y que parece ir vinculada al ejercicio pleno del poder. Por eso mismo, podría ser indicativa a la hora de valorar los vínculos de la reina, también preferentes, con frailes y conventos masculinos.

\section{II.2. Identificación personal y autorrepresentación dominica}

María de Molina ofrece señas de plena identificación personal con la Orden de Predicadores que exceden las manifestaciones de los reyes. Las crónicas destacan su intensa devoción dominica, plasmada por ejemplo en el hecho de poseer reliquias de Santo Domingo -como una túnica áspera- y llevarlas con ella ${ }^{81}$. Otro dato muy significativo es que decidiese enterrarse con el hábito de la orden y,

79 Esther GonzÁLez Crespo, Colección... [ver n. 77], núm. 51, p. 97; Juan LóPeZ, Tercera... [ver n. 3], libro 1, p. 165; CASILlaS GARCÍA, p. 52, n. 99; p. 275; Santiago DOMÍNGUEZ SáNCHEZ, La colección de pergaminos de San Pablo de Valladolid... [ver n. 14], núm. 21, p. 74. Trasladó a los agustinos de Toledo -Enrique FlóREZ, Memorias... [ver n. 71], t. 2, p. 590-, lo cual remitía a Alfonso X, primer promotor de la orden y fundador del convento.

80 Manuel José de Medrano, Historia... [ver n. 63], p. 156. En 1315 compartía con un dominico un asunto en Toro. Esther GONZÁlEZ CRESPO, Colección... [ver n. 77], núm. 17, pp. 50-51.

81 Diego de Colmenares, Historia de la insigne ciudad de Segovia, t. 1, Segovia, 1816, p. 321. 
además, ser representada con él en su túmulo funerario, manifestando públicamente dicha identificación. Sin dudar de su devoción sincera ni de que se sintiese vinculada a la orden por lealtad ${ }^{82}$, queremos subrayar aquí la dimensión política de estas cuestiones.

Sintonizando con la inclinación por las monjas mostrada durante la minoría de Fernando IV, en su primer testamento de $1308^{83}$ doña María disponía ser enterrada y representada con el hábito «de las frayras predicaderas», como una monja dominica. Habían de proporcionárselo antes de morir, e insistía en ser inhumada con él-«que me non metan otros pannos ningunos, sino commo a frayra predicadera»-. Su tumba debía emplazarse en la capilla regia de la catedral de Toledo, en un monumento «en que esté yo figurada con ábito de frayra predicadera» ${ }^{84}$. Singularizaba así su figura respecto a su esposo y los demás reyes y mostraba su interés por su representación, proyección y memoria públicas a perpetuidad; buena prueba de que esta cuestión le interesaba de una forma especial sería que la situase en primer lugar, antes que el resto de disposiciones testamentarias. Recordemos el simbolismo dinástico asociado a las dominicas y el papel de mediación por la familia real que se reconocía a su palabra orante, cuestiones que la reina pudo tener también in mente al querer identificarse con ellas, acaso a fin de plasmar su propio valor de representatividad dinástica y el peso político de su palabra. Manifestaba asimismo lo importante que era para ella que su imagen pública se correspondiese con su verdad personal al insistir respecto a la mortaja, cuestión en la que iba contracorriente. Pero, además, mostraba importantes referentes masculinos: el emperador, cuya tumba mencionaba al determinar que se representase su bulto funerario, y Sancho IV al hacer evidente su autopercepción como su socia equiparada a él, siquiera espacialmente, al disponer ser situada «a par» ${ }^{85}$ suyo.

El vínculo con los frailes de sus señoríos salía reforzado porque les encargaba una buena porción de celebraciones por su alma y los beneficiaba con objetos litúrgicos. Mediadores de su salvación, los responsabilizaba también de procla-

82 Subrayada por Francisco GARCÍA-SERRANO, Preachers... [ver n. 3], p. 64.

83 Santiago Domínguez SÁNCHEZ, La colección de pergaminos de San Pablo de Valladolid... [ver n. 14], núm. 17, pp. 67-70; La colección de pergaminos de San Ildefonso de Toro... [ver n. 40], núm. 15, pp. 8388. Se han comparado las disposiciones litúrgicas de ambos testamentos: Salustiano MORETA Velayos, Notas... [ver n. 5], pp. 182-184.

84 Todas las citas, en Santiago Domínguez SÁNCHEZ, La colección de pergaminos de San Pablo de Valladolid... [ver n. 14], núm. 17, p. 68; La colección de pergaminos de San Ildefonso de Toro... [ver n. 40], núm. 15, p. 84.

85 Ibidem. 
mar y mantener en el tiempo su memoria pública. Así, debían cantarse diez mil misas durante un año -o menos si se pudiese- a partir del día de su muerte, cinco mil donde se mandaba enterrar y otras cinco mil en los conventos de dominicos y franciscanos de Valladolid y Toro. Aunque mencionase a los franciscanos, los dominicos -sobre todo el convento de Toro- eran los únicos favorecidos con legados. Disponía que recibiesen diversos objetos litúrgicos procedentes de su capilla: dos pares de vestimentas con sus túnicas, dalmáticas y albas cada uno y varios frontales de altar el convento de Toro.

Pero el gran depositario de su memoria personal era el convento de dominicos de Toro. Allí establecía importantes celebraciones litúrgicas, hecho asociado a su función como mecenas del convento y a su responsabilidad edilicia. Así, afirmaba que ella lo había comenzado y que era su voluntad terminarlo «a seruiçio de Dios et a onrra de la Orden de Sancto Domingo» ${ }^{86}$. Por este motivo, además de que su hijo Enrique yacía allí y que desde que lo comenzó otorgó a esos frailes la renta del portazgo de Toro, ordenaba que la siguiesen percibiendo hasta finalizar la obra de la iglesia, a la cual debían aplicarla. Después volvería a su hijo, el rey Fernando, o a quienes reinasen después de él. La renta también se asociaba a importantes celebraciones litúrgicas perpetuas por ella. Ordenaba al prior y frailes que cinco de ellos cantasen diariamente sendas misas especiales y que todo el convento hiciese vigilia una vez a la semana; otro día debían decirle una misa cantada en el altar mayor y después tres responsos con sus oraciones; además, todos los frailes habían de hacer un aniversario anual con vigilia y misa cantada a perpetuidad en los que podrían intervenir otros frailes. Les legaba 600 maravedíes anuales para su vestimenta y ordenaba que, sumados a los 200 que otorgaba para la celebración del aniversario, se percibiesen sobre la renta de la judería de Toro. Y pedía a su hijo el rey que aceptase y garantizase la percepción de esta y del portazgo ${ }^{87}$.

Por los mismos motivos, esto es, porque inició la edificación de San Pablo de Valladolid y tenía voluntad de acabarlo y porque allí yacía su hijo don Alfonso, establecía otras disposiciones referentes a este convento. Desde que comenzó a labrarlo le dio el portazgo de Valladolid y ordenaba que lo tuviesen hasta finalizar la iglesia y el convento. Después, igualmente, debía retornar a la Corona. En este caso, no había más legados. Es claro que la reina se identificaba personalmente

86 Santiago Domínguez SÁncheZ, La colección de pergaminos de San Pablo de Valladolid... [ver n. 14], núm. 17, p. 69; La colección de pergaminos de San Ildefonso de Toro... [ver n. 40], núm. 15, p. 86.

87 Fernando IV lo confirmaba el 6 de febrero de 1308. Santiago DOMÍNGUEZ SáNCHEZ, La colección de pergaminos de San Pablo de Valladolid... [ver n. 14], núm. 18, p. 71. 
con el convento de Toro y no con el de Valladolid en 1308. Una preferencia que quizá se explique por los fuertes vínculos personales que tuvo con su villa toresana, donde dio a luz a su primera y última hija, murió su primer hijo varón ${ }^{88}$ y realizó diversas obras de promoción dominica; además, allí también nacieron personas cercanas como su ama, María Fernández Coronel, a la que nombraba testamentaria. La reina establecía por testamentario mayor a su hijo el rey y confiaba en que haría cumplir sus disposiciones porque así alcanzaría la bendición de Dios y la suya y, además, dada «la lazería» que llevó con él «en le ayudar para lo fazer regnar et tan uerdaderamient lo amé yo siempre, que so çierta de la su lealdat e del su buen entendimiento que lo fará assíi ${ }^{89}$. Ayuda, lealtad y buen entendimiento, aspectos que la reina pudo haber encontrado también en su relación con los frailes dominicos y que todos los indicios apuntan a que ella misma desarrolló.

Diversos conventos de dominicos y franciscanos eran asimismo beneficiados con legados. Llama la atención que se tratase de las parejas de conventos mendicantes instalados en la mayoría de las poblaciones de Castilla y León más vinculadas a la Corona: Burgos, Palencia, Valladolid, Toledo, Salamanca, Zamora, Toro y Ciudad Rodrigo ${ }^{90}$. La reina debía sentirse partícipe de ese vínculo. Muy probablemente, estos legados visibilizan los epicentros de sus contactos urbanos y mendicantes, concretamente dominicos, en Castilla y León, aquellos que acaso la apoyaron durante la minoría de su hijo. Contactos, por otra parte, numéricamente equilibrados entre reinos. Es posible que la importancia de estos enclaves dominicos decidiese la selección de los franciscanos dado que los conventos de frailes menores eran más numerosos.

El segundo y definitivo testamento de María de Molina, fechado el 29 de junio de $1321^{91}$, se realizó en los aposentos que ocupaba enferma en el convento de San Francisco de Valladolid. Pese a ello, los franciscanos no eran mencionados. Y, si bien seguía mostrando su preferencia dominica, introducía cambios de gran relevancia ${ }^{92}$.

88 Rafael Floranes y ENCINAS, Memorias... [ver n. 61], pp. 98 y 100.

89 Santiago DomíngueZ SÁNCHEZ, La colección de pergaminos de San Pablo de Valladolid... [ver n. 14], núm. 17, p. 70; La colección de pergaminos de San Ildefonso de Toro... [ver n. 40], núm. 15, p. 88.

90 También menciona un supuesto emplazamiento mendicante en Palenzuela que no hemos documentado. Este lugar, muy vinculado a la reina, contaba con un monasterio cisterciense.

91 Santiago Domínguez Sánchez, La colección de pergaminos de San Pablo de Valladolid... [ver n. 14], núm. 23, pp. 76-82; La colección de pergaminos de San Ildefonso de Toro... [ver n. 40], núm. 17, pp. 90-99.

92 Véanse las reflexiones de Patricia Rochwert-Zuili, El mecenazgo... [ver n. 7], pp. 2-5. 
Destaca el hecho de haber modificado su lugar de enterramiento al decidir que fuese en el «mío monesterio» de Santa María de Valladolid, resaltando su vínculo señorial con las monjas cistercienses. Este hecho coincidía, además, con otro cambio importante relativo al hábito: no pedía que antes de morir le diesen el de las monjas dominicas, sino el «ábito de los frayres predicadores, en que muera e me entierren con él ${ }^{93}$, un cambio significativo aunque se tratase de la misma orden religiosa. Además, en este caso no estipulaba cómo había de ser su bulto funerario, pues ni siquiera trataba esta cuestión: ¿quizá porque entendía que el enterrarse sola ya singularizaba debidamente su figura pública? El hecho de que, en este caso, el hábito masculino quedase circunscrito al espacio de lo no público, ¿indicaría su identificación personal, íntima, con la encarnación masculina del carisma dominico? Recordemos que los frailes se dedicaban al ejercicio de la palabra pública, la predicación pacificadora y conciliadora, así como a la adquisición del saber. Palabra, sabiduría y conciliación eran también conceptos aplicables a la acción y a la imagen política de doña María y muy evidentes en su representación cronística. ¿De algún modo el hábito dominico masculino constituía el cauce representativo ideal para una figura política femenina signada por aquellos atributos?, ¿podía significar también que dicha figura política había llegado al culmen de su autonomía y capacidad de acción en un mundo de hombres?, ¿eran éstas cuestiones que habían de mantenerse ocultas en el sepulcro, como si constituyesen el corazón de la figura funeraria exterior? Al menos, la representación funeraria de doña María que nos ha llegado la presenta vestida de dama y con un rosario como único elemento de identificación dominica; al parecer, en su momento portaba también una corona hoy día desaparecida.

La memoria dinástica se asociaba al monasterio femenino del Císter, no a los dominicos. Afirmaba que Fernando IV había visto que «era a mucho servicio de Dios e a pro e salud de las almas del rey don Sancho e de aquellos onde nos venimos», así como para la salvación de ellos y de aquellos «que de nos vernán» ${ }^{94}$, situándose ella en primera persona en la cadena de referentes dinásticos. El rey había donado al monasterio por estas razones una renta de 50.000 maravedíes anuales. Doña María disponía que las monjas rogasen por las almas de Sancho IV, Fernando IV y de ella, así como por la vida y salud de Alfonso XI. Asimismo, que

93 Las dos citas, en Santiago Domínguez Sánchez, La colección de pergaminos de San Pablo de Valladolid... [ver n. 14], núm. 23, p. 77; La colección de pergaminos de San Ildefonso de Toro... [ver n. 40], núm. 17, p. 91.

94 Santiago Domínguez SÁnchez, La colección de pergaminos de San Pablo de Valladolid... [ver n. 14], núm. 23, p. 79; La colección de pergaminos de San Ildefonso de Toro... [ver n. 40], núm. 17, p. 95. 
celebrasen aniversarios anuales por los tres y por el rey Alfonso tras su muerte. Finalmente, volvía a subrayar su papel dinástico y se equiparaba a los titulares de la Corona al establecer que una mujer del linaje del rey don Sancho «e de mí ${ }^{95}$, por línea directa, fuese monja y señora del monasterio señalando un paralelo con el de las Huelgas de Burgos.

Los frailes veían drásticamente reducido su protagonismo. De las 10.000 misas que debían cantarse por su alma ya no responsabilizaba a ninguno, ni dominico ni franciscano. Además, circunscribía su celebración al monasterio de Santa María y a las iglesias y monasterios de Valladolid al igual que las capellanías perpetuas que fundaba. En este caso se manifestaba una plena identificación entre la reina y su ciudad de Valladolid en notorio contraste con el primer testamento. Por otra parte, el convento de Toro, aunque seguía constituyendo un espacio de singularización de su persona, ya no era el depositario de su memoria perpetua y reducía los encargos litúrgicos. Los frailes debían celebrar un aniversario anual por su alma con vigilia y misa cantada en el altar mayor; además, todos los que fueren de misa debían decir misas por ella ese día.

Cierto que mantenía de forma casi literal sus disposiciones sobre las rentas a percibir por los dominicos de Toro y Valladolid para finalizar sus conventos. Tan solo especificaba que los de Toro conservasen el portazgo hasta que estuviese finalizada la iglesia y «la claustra mayor», y después que quedase en manos de su nieto el rey Alfonso o de quienes reinaren tras él. Reiteraba lo mismo respecto al portazgo de Valladolid en relación con la edificación de San Pablo. E insistía en que por las celebraciones en Toro se percibiría una renta anual sobre la judería de la villa.

En esta ocasión no mencionaba el elenco de conventos dominicos y franciscanos que coincidían con las ciudades más vinculadas a la monarquía en Castilla y León. Sin negar que acaso los hubiese beneficiado entre sus dos testamentos ${ }^{96}$, puede pensarse que quizá ya no necesitaba enfatizar tanto su asociación personal con los frailes. También sería significativo lo que defiende la tradición: que legó a su monasterio cisterciense femenino las reliquias que tenía de Santo Domin$\mathrm{go}^{97}$; de haber sido así, parece haberle interesado su identificación personal, que las reliquias siguiesen estando con ella y no en los templos dominicos. De algún modo, María de Molina identificaba su obra culmen y a sí misma vestida de fraile dominico con el fundador de la Orden de Predicadores.

95 Santiago Domínguez SánCHeZ, La colección de pergaminos de San Pablo de Valladolid... [ver n. 14], núm. 23, pp. 80; La colección de pergaminos de San Ildefonso de Toro... [ver n. 40], núm. 17, p. 96.

96 Así lo piensa Salustiano Moreta Velayos, Notas... [ver n. 5], p. 184.

97 Luis Alonso Getino, Dominicos... [ver n. 76], p. 31. 
Los notorios cambios entre un testamento y otro, sobre todo en el emplazamiento, vestimenta y autorrepresentación funeraria de la reina y en sus vínculos religiosos identificativos, no dejarían de tener que ver con la evolución de su figura política hacia la singularización, el poder y la autoridad consolidada. Sabemos que esto fue así en su vida pública, lo cual refuerza el valor de la representación simbólica aportada por la espiritualidad.

\section{CULTURA CORTESANA Y PROMOCIÓN DOMINICA}

Si la alianza entre la Corona y la Orden de Predicadores fue elemento decisivo de la cultura política de estos años y si tanto el rey como la reina tuvieron en esto un papel protagonista, cabe añadir el peso de la corte. Da la impresión de que una parte destacada de dicha cultura política se encarnó en una nueva cultura cortesana partícipe de la misma. Dicha cultura cortesana habría ido ganando importancia durante el reinado de Sancho IV, pero quizá de forma especial en la primera tutoría de la reina y en torno a su persona. Afirmamos esto con precaución porque hace falta un estudio más detenido. Con todo, apuntamos algunas características.

Teniendo en cuenta que también participaron de este fenómeno otras órdenes mendicantes, es preciso subrayar el peso dominante de lo dominico, pues del círculo cortesano brotaron diversas iniciativas fundacionales de conventos y monasterios de la Orden de Predicadores. El hecho de que los integrantes de la Corte compartiesen con la Corona la tarea de promoción dominica constituía un fenómeno novedoso, como también lo fue el protagonismo de las mujeres que, además, parecen haberlo iniciado. A través suyo, esta cultura cortesana dominica remitía a la reina como figura de autoridad y poder y se situaba al servicio de su memoria ${ }^{98}$. Por otra parte, las primeras iniciativas se circunscribieron a su área de dominio en el reino de León, Toro y sus inmediaciones, en algún caso como resultado de su intervención directa.

Así, en fechas muy próximas, entre las tutorías ejercidas por doña María, dos mujeres del círculo cortesano decidieron fundar sendos monasterios de dominicas, hecho que también coincidía con el mayor peso de las monjas durante la recién finalizada minoría de Fernando IV. En 1305, doña Teresa Al-

98 María del Mar GRAÑa CID, Reinas, infantas y damas de corte en el origen de las monjas mendicantes castellanas (c. 1222-1316). Matronazgo espiritual y movimiento religioso femenino, en Blanca GARÍ (ed.), Redes femeninas de promoción espiritual en los Reinos Peninsulares (siglos XIII-XVI), Roma, 2013, pp. 21-43. 
fonso, tía de doña María, cedió al monasterio de Santa María de las Dueñas de Zamora la aldea de San Cebrián de Mazote, a cuatro leguas de Toro, donde las monjas debían fundar monasterio. La fundación implicaba aumentar el radio de influencia de los dominicos de Toro, pues entre sus disposiciones litúrgicas establecía la celebración de un aniversario anual al que debían acudir al menos diez frailes de aquel convento, que recibirían de las monjas veinte cargas de trigo anuales ${ }^{99}$. Por su parte, en su testamento de 1307 doña Teresa Gil, mujer muy próxima a los reyes, disponía la fundación de otro monasterio de dominicas sin especificar lugar, aunque sí denominación, San Salvador. Nombraba testamentarios a dominicos importantes como el obispo de Ciudad Rodrigo o el prior de San Pablo de Valladolid y ponía de manifiesto sus vínculos con los establecimientos dominicos de Valladolid y Zamora además de su preferencia por los frailes, entre otras cosas al disponer que su cuerpo permaneciese en Santo Domingo de Zamora mientras se edificaba su monasterio. Es un documento de gran interés porque no solo refleja la devoción personal, sino todo un entramado de relaciones del que formaban parte destacados establecimientos dominicos de los dos reinos, lo cual denota que el círculo cortesano participaba de algún modo de la red clientelar que cohesionaba el territorio soberano de la Corona. La reina María era incluida como testamentaria mayor junto a Fernando IV y el rey Dionís de Portugal, una importante referencia de autoridad. Al parecer, habría sido doña María quien, cumpliendo esta función, decidió finalmente que el monasterio se estableciese en Toro y cambiase la advocación por Sancti Spiritus ${ }^{100}$.

Estas primeras promociones se emplazaron en el área que más interesaba a María de Molina por entonces, su villa de Toro y cercanías, y favorecieron a los frailes de su convento. Además, situaban a la reina en un plano de autoridad y poder sobre las mismas. Al menos en la iniciativa de doña Teresa Alfonso, la fundación se vinculaba a la memoria reginal al establecer que las monjas hiciesen oración diaria por la reina, a quien solicitaba que lo hiciese cumplir ${ }^{101}$. De esta forma, el impulso cortesano femenino reforzaba la imagen pública de la reina, su

99 Mencionada como tía de la reina y en relación con Toro y el infante Enrique en las cuentas de 1294. Asunción LÓPEZ Dapena, Cuentas... [ver n. 69], p. 510; Hernando del CaSTILlO, Segunda parte... [ver n. 4], ff. 55r-56r. Recordemos los vínculos dominicos de la familia. Luis ALONSO GETINO, Dominicos... [ver n. 76], p. 21.

100 Hernando del CaSTILlo, Segunda parte... [ver n. 4], ff. 58r-60r. Adeline RuCQUOI, Le testament de doña Teresa Gil, en Femmes, mariages, lignages, XII ${ }^{e}$-XIV ${ }^{e}$ siècles. Mélanges offerts à Georges Duby, Bruxelles, 1992, pp. 305-323.

101 Hernando del CASTILlO, Segunda parte... [ver n. 4], ff. 55r-56r. 
posición de poder y autoridad, su ejercicio señorial y memoria perpetua, y estas cuestiones se vinculaban a la implantación de la Orden de Predicadores en ámbitos de su máxima influencia.

Tras esta primera fase hubo algún otro proyecto fundacional coincidente con la segunda tutoría de doña María, pero ya no femenino, así como cesiones de bienes a establecimientos dominicos preexistentes. Señalemos casos como el de doña Inés de Limoges, esposa del Canciller Mayor de Castilla, don Alfonso Godínez - «persona de toda la confianza del rey» ${ }^{102}-$ y próxima a la reina durante la minoría de Alfonso XI: esta dama favoreció al convento de San Esteban de Salamanca legando toda su hacienda en $1318^{103}$. Hay asimismo datos sobre personajes masculinos de impronta cortesana relacionados con conventos dominicos muy vinculados a la Corona como San Pablo de Valladolid, en algún caso en fecha posterior ${ }^{104}$, o bien los descendientes de personas próximas a los reyes acabaron obteniendo patronatos en conventos vinculados a ellos, como ejemplifican los descendientes de Alvar Rodríguez Osorio, persona próxima a Sancho IV, en Santo Domingo de Benavente ${ }^{105}$. Sabemos también que personajes de la familia real o de la corte, con nombres tan importantes como los infantes don Juan y don Juan Manuel fueron activos promotores de conventos dominicos en torno a $1320^{106}$. Hacen falta estudios particulares para valorar el alcance de estos aspectos.

\section{CONCLUSIONES}

La promoción de la Orden de Predicadores fue uno de los rasgos característicos de la cultura política de los reinados de Sancho IV, Fernando IV y Alfonso XI. No se trató de una novedad introducida por Sancho IV y María de Molina, como tampoco el vínculo estrecho con los detentadores del trono o la identificación con la dinastía, el reino y la idea de soberanía. Estos aspectos se remontaban a la figura inaugural de Fernando III y su definición dinástica había sido completada

102 Mercedes Gaibrois, Historia... [ver n. 3], t. 1, p. 69.

103 Juan López, Tercera... [ver n. 3], libro 1, p. 169.

104 Santiago Domínguez SÁnchEZ, La colección de pergaminos de San Pablo de Valladolid... [ver n. 14], núm. 19, pp. 72-73; núm. 25, pp. 83-84.

105 José Ledo DEL POZO, Historia... [ver n. 9], p. 343.

106 Hernando del CASTILlo, Segunda parte... [ver n. 4], ff. 113rv; Santiago DomínGUEZ SÁnCHEZ, La colección de pergaminos de San Pablo de Valladolid... [ver n. 14], núm. 36, pp. 137-149; Manuel Mª DE LOS HoYOS, Material inédito... [ver n. 10], t. 2, p. 67. 
por Alfonso X. La continuidad dinástica debió importar mucho a unos reyes que batallaron por su legitimidad y esta sería una de las razones principales de su querencia dominica.

Los acentos diferenciales de la monarquía de Sancho IV y doña María radicarían en el establecimiento de un vínculo casi privativo con los dominicos o, cuando menos, una marcada preferencia respecto a otras órdenes, sobre todo en el caso del rey. La identificación del territorio de ejercicio soberano con los establecimientos de la Orden de Predicadores iniciada por Fernando III había nacido con impronta castellana y fue en ese sentido como Alfonso X desarrolló su política pro-dominica en sus reinos. La novedad de don Sancho habría radicado en emplear esta dimensión geo-soberana en un sentido inverso: comenzó haciéndose fuerte en León para avanzar hacia Castilla y acabar englobando su promoción de la orden en el marco general de sus reinos. Pero incidió en lo leonés y no tanto en lo castellano, línea en la que situaríamos los privilegios generales, que también fueron cosa suya tanto en número como en amplitud de contenidos. Por lo demás, la relación que entabló siendo infante entre la promoción de conventos y la personalización política además del ejercicio señorial, los vínculos clientelares y la aspiración al poder regio, constituyó una combinación nueva en relación con la promoción dominica. Los vínculos de servicio, ya establecidos en los reinados anteriores, adquirían ahora otra dimensión: más intensamente personales y continuados en el tiempo, generaban una red clientelar más compacta, circunscrita a ámbitos territoriales concretos, y en la que los conventos funcionaban como principales engarces. Todo ello contribuía a construir una figura política que podía afianzarse pasando por encima de su ilegitimidad hasta el punto de que el acceso a la Corona y el ejercicio soberano parecían corresponderse con el respaldo dominico. Mediante el privilegio y la protección, Sancho IV acabó poniendo a su servicio a la entera Orden de Predicadores. Fue este uno de los factores que incidieron en pro del afianzamiento de su figura regia y de su dominio soberano del reino, que asimismo parece haber caminado hacia una cierta cohesión con tintes nacionalistas de la mano de dicha institución y en la que figurarían plenamente integrados, siquiera en esta dimensión, León y Castilla.

El modelo de monarquía fue característico respecto al papel de la reina. Tanto doña Berenguela como doña Violante habían sido activas en la promoción mendicante y colaboraron con los reyes, pero no parece haberse dado una implicación personal tan intensa como la de María de Molina en sus fundaciones señoriales ni un impulso similar a los frailes. Las acciones dominicas de la reina contribuyeron a definirla como un sujeto político con autoridad propia y 
una imagen pública positiva. Siguiendo la pauta de don Sancho en Benavente, optó también por frailes, cuyo saber y capacidad pastoral y política incidían en los ámbitos de la propaganda y el poder afectando a la vida política del reino; sin duda, su figura reginal adquiría un relieve peculiar en relación con ellos. Por otra parte, la reina no se habría limitado a cooperar con don Sancho, se percibe una situación de equiparación en este ámbito. Cierto que no otorgaba privilegios ni protección directa, pero sí beneficios materiales y otras formas de apoyo; su intensa involucración fundacional reforzaba los vínculos de identificación y fidelidad y su liderazgo sobre los frailes. A su modo, se habría integrado en la red clientelar como señora con autoridad y poder en términos similares al rey, habría incidido en el tejido político, mientras promovía la visibilidad de los titulares de la Corona y de la familia real fundando conventos y enterrando a sus hijos en ellos.

Todo esto debió favorecer que doña María contase con el apoyo de la orden durante las minorías de su hijo y nieto. Su figura pública se habría reforzado a lo largo de estos años gracias, en una parte destacada, al apoyo dominico. La política dominica de los reyes niños mantuvo las líneas anteriores, apuntaló la legitimidad dinástica sobre todo a través de los monasterios femeninos y favoreció a los frailes aunque se volviese más prudente en la concesión de privilegios generales, quizá para mantener el equilibrio con el resto de poderes, sobre todo las ciudades. La continuidad de las grandes líneas diseñadas por Sancho IV cuando estos reyes asumieron la corona muestra su éxito. Con todo, es cierto que no volvemos a encontrar un modelo similar en la actividad de las reinas consortes hasta la figura clave de Catalina de Lancaster ${ }^{107}$.

Otra clave de la cultura política del reinado habría sido el gran peso de la corte y la activa implicación de sus miembros en las líneas trazadas por los reyes. Sin duda, dado el estrecho vínculo trabado con conventos y monasterios, algunos o bastantes de ellos formaron parte de una red de contactos e, incluso, pudieron constituir una especie de ampliación del espacio cortesano. También resulta llamativo el interés por el área leonesa. Habría que intentar reconstruir estas redes y sus espacios sin olvidar que tanto don Sancho como doña María se hicieron fuertes fundando conventos de frailes dominicos en el reino de León.

107 María del Mar GRAÑA CID, Catalina de Lancaster, la Orden de Predicadores y la reginalidad: las políticas conventuales, en Edad Media. Revista de Historia, 18 (2017), pp. 75-100. 
Si uno de los fines de la cultura letrada propia del molinismo habría sido la justificación de la figura de Sancho IV y la representación de doña María como figura política que hizo de la palabra su instrumento de acción preferente, parece claro que a ello contribuiría la política de promoción dominica desarrollada por ambos. En esta línea cabría entender igualmente que doña María dispusiese vestirse como un fraile dominico en su último y definitivo testamento.

\section{REFERENCIAS BIBLIOGRÁFICAS}

Aguadé NiETO, Santiago, Alfonso X y las órdenes mendicantes, en Saxonia Franciscana, 10 (1998), pp. 277-302.

Alonso Getino, Luis, Dominicos españoles confesores de reyes, Madrid, 1917.

Álvarez RodrígueZ, Alicia, Los concejos de Zamora y Benavente y su relación con los conventos de la Orden de Predicadores durante los siglos XIII-XV, en Studia Historica. Historia Medieval, 33 (2015), pp. 263-287.

ÁlVAREZ RODRÍGUEZ, Alicia, Los frailes y la «cura animarum» como actividad conflictiva en Zamora, Toro y Benavente durante la Baja Edad Media, en Edad Media. Revista de Historia, 19 (2018), pp. 218-240.

ARCO y GaraY, Ricardo del, Sepulcros de la Casa real de Castilla, Madrid, 1954.

Carmona Ruiz, María Antonia, María de Molina, Barcelona, 2005.

Casillas García, José Antonio, El convento de San Pablo de Burgos. Historia y arte, Salamanca-Burgos, 2003.

Castillo, Hernando del, Primera parte de la historia general de Sancto Domingo y de su Orden de Predicadores, Madrid, 1584.

Castillo, Hernando del, Segunda parte de la bistoria general de Sancto Domingo y de su Orden de Predicadores, Valladolid, 1592.

Colmenares, Diego de, Historia de la insigne ciudad de Segovia, t. 1, Segovia, 1816.

CRÓNICAS de los reyes de Castilla. Desde don Alfonso el Sabio hasta los católicos don Fernando y doña Isabel, t. 1, Madrid, 1953.

Domínguez SáncheZ, Santiago, El convento dominico de San Pablo de Palencia (12201600). Breve reseña histórica y colección diplomática, t. 1, Salamanca, 2017.

Domínguez SÁNCHEZ, Santiago, La colección de pergaminos de San Ildefonso de Toro (1127-1589): un vademécum para la diplomática pontificia, León, 2019.

Domínguez SÁNCHeZ, Santiago, La colección de pergaminos de San Pablo de Valladolid (1276-1605): un vademécum para la diplomática procesal pontificia, León, 2020.

Dorado, Bernardo, Compendio bistórico de la ciudad de Salamanca, Salamanca, s.a.

FERnández Ruiz, Raquel del Carmen, Colección diplomática del monasterio de Santo Domingo de Benavente (1228-1390), Benavente, 2000.

Floranes y ENCINAS, Rafael, Memorias para la historia de la ciudad y tierra de Toro, Zamora, 1994. 
FLÓREZ, Enrique, Memorias de las reinas católicas, t. 2, Valladolid, 2002.

GAIBROIS, Mercedes, Fray Munio de Zamora, en Abbandlungen aus dem Gebiete der mittleren und neueren Geschichte und ibrer Hilfswissenschaften. Eine Festgabe zum siebzigsten Geburtstag Geh. Rat Prof. Dr. Heinrich Finke, Münster, 1925, pp. 135-154. Gaibrois de Ballesteros, Mercedes, María de Molina. Tres veces reina, Madrid, 1967. Gaibrois De Ballesteros, Mercedes, Historia del reinado de Sancho IV de Castilla, 3 t., Madrid, 2019.

Galindo Romeo, Pascual, Catálogo del Archivo del Monasterio de Sancti Spiritus de Toro, en Archivos Leoneses, 30 (1976), pp. 205-236.

García Cuetos, Pilar, El convento dominico de Nuestra Señora del Rosario de Oviedo. Historia y arquitectura, Oviedo, 2001.

GARCÍA FERNÁNDEZ, Ernesto, Dominicos y franciscanos en el País Vasco (siglos XIII-XV), en VI Semana de Estudios Medievales, Logroño, 1996, pp. 213-233.

García-SERrano, Francisco, Preachers of the City. The Expansion of the Dominican Order in Castile (1217-1348), New Orleans, 1997.

GÓmEZ REDONDO, Fernando, El molinismo: un sistema de pensamiento letrado (12841350), en Antonia MARTínez PÉREZ y Ana Luisa BAQUERO Escudero (eds.), Estudios de literatura medieval. 25 años de la Asociación Hispánica de Literatura Medieval, Murcia, 2012, pp. 43-73.

GonZÁlez CRespo, Esther, Colección documental de Alfonso XI. Diplomas reales conservados en el Archivo Histórico Nacional, Sección de Clero. Pergaminos, Madrid, 1985.

GonZÁleZ JimÉneZ, Manuel, Sancho IV, infante, en Historia, Instituciones, Documentos, 28 (2001), pp. 151-216.

GONZÁLEZ MíNGUEZ, César, Itinerario y regesta de Fernando IV de Castilla (1295-1312), Bilbao, 2015.

GRAÑa CID, María del Mar, Reinas, infantas y damas de corte en el origen de las monjas mendicantes castellanas (c. 1222-1316). Matronazgo espiritual y movimiento religioso femenino, en Blanca GARÍ (ed.), Redes femeninas de promoción espiritual en los Reinos Peninsulares (siglos XIII-XVI), Roma, 2013, pp. 21-43.

GRAÑA CID, María del Mar, Berenguela I y Fernando III, promotores de las órdenes mendicantes en Castilla, en Manuel PELÁEZ DEL ROSAL (dir.), El franciscanismo: identidad y poder, Córdoba, 2016, pp. 119-141.

GRAÑA CID, María del Mar, Catalina de Lancaster, la Orden de Predicadores y la reginalidad: las politicas conventuales, en Edad Media. Revista de Historia, 18 (2017), pp. 75-100.

Graña CID, María del Mar, The Mendicant Policies of the Queens of Castile in the 13th Century: the Implantation of Convents, en Nikolas JASPERT y Imke JUST (eds.), Queens, Princesses and Mendicants: Close Relations in a European Perspective, Zurich, 2019, pp. 65-83.

GuTiÉRreZ BAÑos, Fernando, Las empresas artísticas de Sancho IV el Bravo, Burgos, 1997. 
Hoyos, Manuel $\mathrm{M}^{\mathrm{a}}$ de los, Material inédito dominicano español. Registro documental, t. 2, Valladolid, 1962.

Ledo Del Pozo, José, Historia de la nobilísima villa de Benavente, Salamanca, 1970.

LiNEHAN, Peter, La Iglesia española y el papado en el siglo XIII, Salamanca, 1975.

LineHan, Peter, Las dueñas de Zamora. Secretos, estupro y poderes en la Iglesia española del siglo XIII, Barcelona, 2000.

López, Juan, Tercera parte de la historia general de Sancto Domingo y de su Orden de Predicadores, Valladolid, 1613.

López Dapena, Asunción, Cuentas y gastos (1292-1294) del rey D. Sancho IV el Bravo (1284-1295), Córdoba, 1984.

Martínez, Eduardo, Colección diplomática del Real Convento de Santo Domingo de Caleruega, Vergara, 1931.

Medrano, Manuel José de, Historia de la provincia de España de la Orden de Predicadores. Segunda parte, t. 1, Madrid, 1729.

MiURA ANDRADES, José María, Frailes, monjas y conventos. Las órdenes mendicantes y la sociedad sevillana bajomedieval, Sevilla, 1998.

Moreta Velayos, Salustiano, Notas sobre el franciscanismo y el dominicanismo de Sancho IV y María de Molina, en VI Semana de Estudios Medievales, Logroño, 1996, pp. 171-184.

NieTo Soria, José Manuel, Sancho IV de Castilla (1284-1295), Gijón, 2014.

NiEva OCAMPO, Guillermo, Los dominicos en Castilla. La génesis de una corporación privilegiada en la Baja Edad Media, en Guillermo NIEVA OCAMPO et al. (eds.), Servir a Dios y servir al rey: el mundo de los privilegiados en el ámbito hispánico (siglos XIIIXVIII), Salta, 2011, pp. 13-47.

Pelaz FloRes, Diana, «Reynante(s) en vno». Fundamentación teórica del poder de la pareja regia en la Corona de Castilla durante la Baja Edad Media, en Anuario de Estudios Medievales, 48/2 (2018), pp. 845-869.

Pepin, Paulette Lynn, María de Molina, Queen and Regent. Life and Rule in Castile-León, 1259-1321, London, 2016.

PÉREZ VIDAL, Mercedes, Sancti Spiritus de Toro: arquitectura y patronazgo femenino, en Liño. Revista Anual de Historia del Arte, 14 (2008), pp. 9-21.

Ríos DE La LlaVE, Rita, The Role of the Mendicant Orders in the Political Life of Castile and León in the Later 13th Century, en Religion and Political Change in Europe: Past and Present, Pisa, 2003, pp. 21-33.

Ríos DE LA LLAVE, Rita, Mujeres de clausura en la Castilla medieval: el monasterio de Santo Domingo de Caleruega, Alcalá de Henares, 2007.

RISCO, Manuel, Iglesia de León y monasterios antiguos y modernos de la misma ciudad, Madrid, 1792.

Rochwert-Zuili, Patricia, El mecenazgo y patronazgo de María de Molina. Pruebas e indicios de unos recursos propagandísticos y dinásticos, en E-Spania (2016). 
Romero FernándeZ-Pacheco, Juan Ramón, Santo Domingo el Real de Madrid. Ordenación económica de un señorío conventual durante la Baja Edad Media (1219-1530), Salamanca, 2008.

RUCQUOI, Adeline, Valladolid en la Edad Media, t. 1, Génesis de un poder, Valladolid, 1987.

RUCQUOI, Adeline, Le testament de doña Teresa Gil, en Femmes, mariages, lignages, XII ${ }^{e-}$ XIVe siècles. Mélanges offerts à Georges Duby, Bruxelles, 1992, pp. 305-323.

SERrano RodrígueZ, Eugenio, Toledo y los dominicos en la época medieval. Instituciones, economía, sociedad, Cuenca, 2014.

ZATARAÍN FERNÁNDEZ, Melchor, Apuntes y noticias curiosas para formalizar la historia eclesiástica de Zamora y su diócesis, Zamora, 1898.

ZURDO, Francisco, Zamora dominicana, Zamora, 1994. 
